
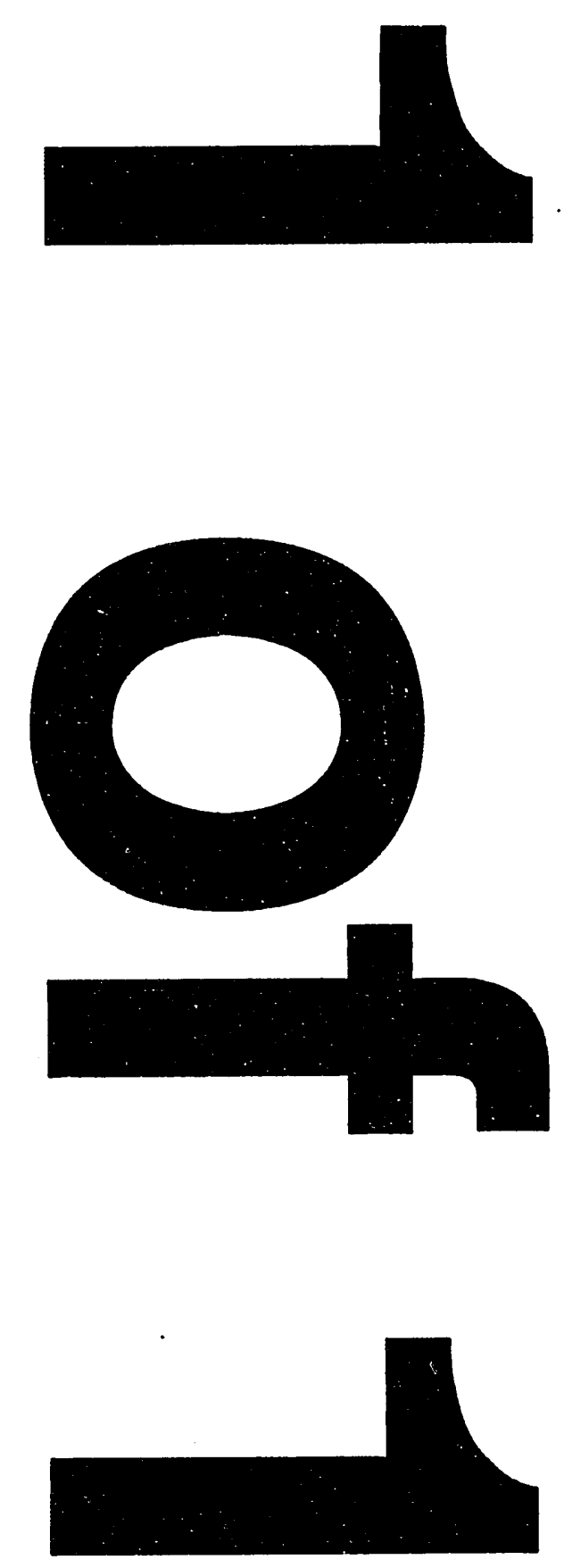
NUREG/CR-5358

ORNL/TM-11572

RM

\section{Review of ASME Code Criteria for Control of Primary Loads on Nuclear Piping System Branch Connections and Recommendations for Additional Development Work}

Manuscript Completed: September 1993

Date Published: November 1993

Prepared by

E. C. Rodabaugh, R. C. Gwaltney, S. E. Moore

Oak Ridge National Laboratory

Managed by Martin Marietta Energy Systems, Inc.

Oak Ridge National Laboratory

Oak Ridge, TN 37831-6285

\section{Prepared for \\ Division of Engineering Office of Nuclear Regulatory Research \\ U.S. Nuclear Regulatory Commission \\ Washington, DC 20555-0001 \\ NRC FIN B0474}




\begin{abstract}
This report collects and uses available data to reexamine the criteria for controlling primary loads in nuclear piping branch connections as expressed in Section III of the ASME Boiler and Pressure Vessel Code. In particular, the primary load stress indices given in NB-3650 and NB-3683 are reexamined. The report concludes that the present usage of the stress indices in the criteria equations should be continued. However, the complex treatment of combined branch

mation. Therefore, it is recommended that this combined loading evaluation procedure be replaced for primary loads by the separate leg evaluation procedure specified in NC/ND-3653.3(c) and NC/ND-3653.3(d). No recommendation is made for fatigue or secondary load evaluations for Class 1 piping. Further work should be done on the development of better criteria for treatment of combined branch and run moment effects.
\end{abstract} and run moments is not supported by available infor- 


\section{Contents}

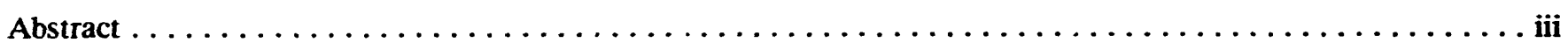

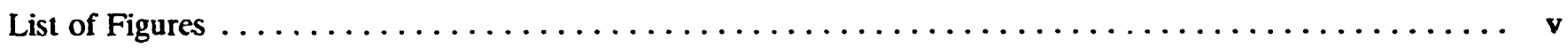

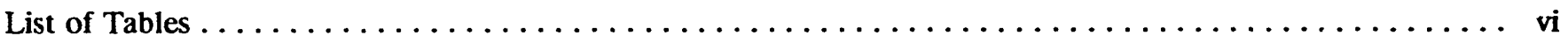

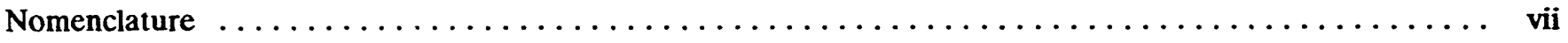

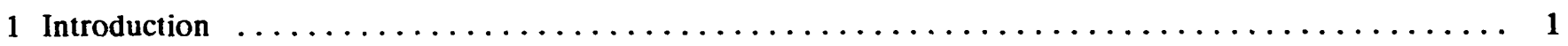

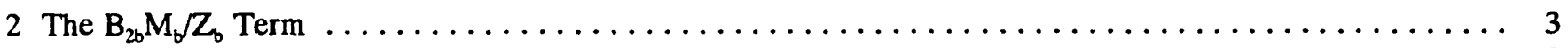

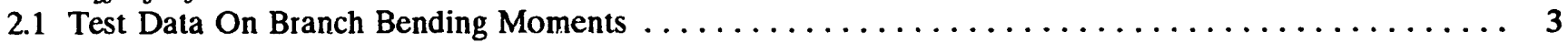

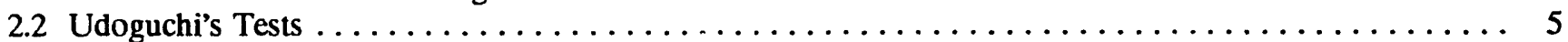

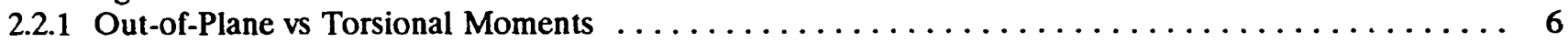

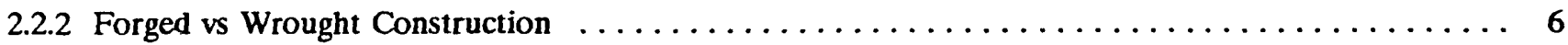

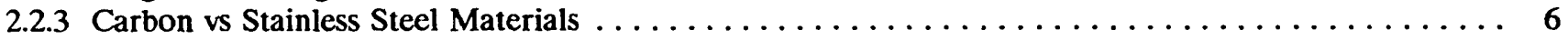

2.2.4 Combined Out-of-Plane Moment and Torsion Tests $\ldots \ldots \ldots \ldots \ldots \ldots \ldots \ldots \ldots \ldots \ldots \ldots \ldots$

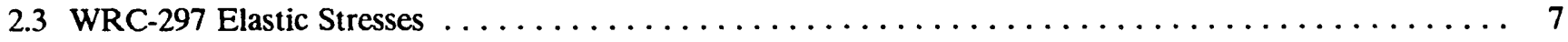

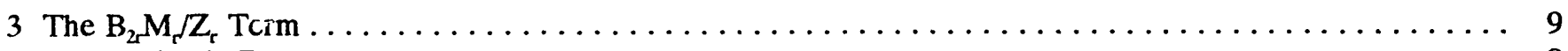

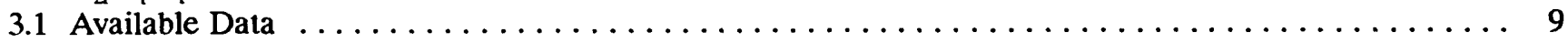

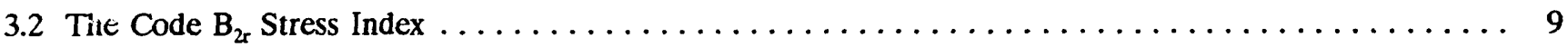

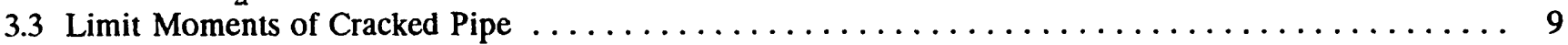

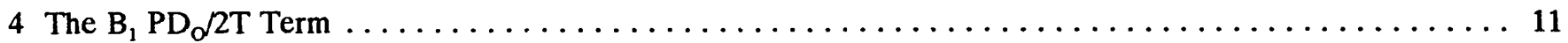

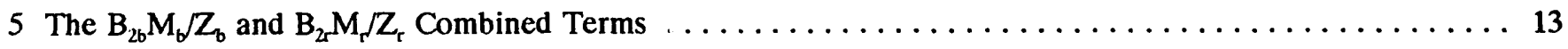

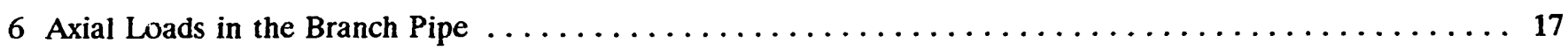

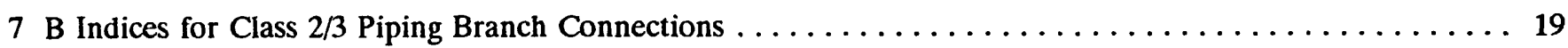

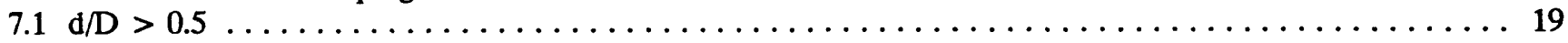

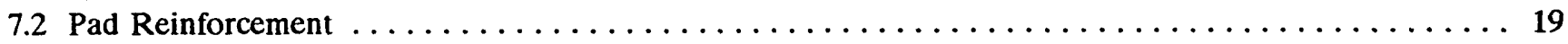

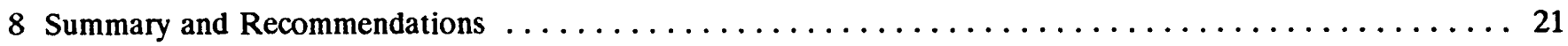

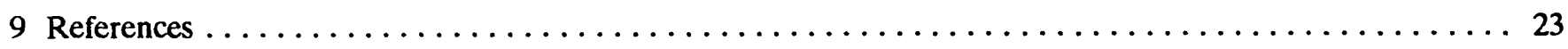

Figures

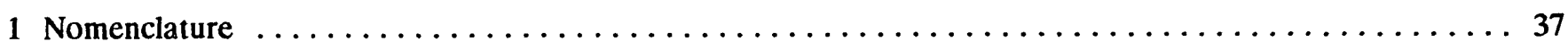

2 From Udoguchi (1973), Combined Bending and Torsion Test $\ldots \ldots \ldots \ldots \ldots \ldots \ldots \ldots \ldots \ldots$

3 Cracked Pipe Model for Run Pipe Bending Moment $\ldots \ldots \ldots \ldots \ldots \ldots \ldots \ldots \ldots \ldots \ldots \ldots$

4 Illustrations of Combined Branch and Run Moments $\ldots \ldots \ldots \ldots \ldots \ldots \ldots \ldots \ldots \ldots \ldots \ldots \ldots$

Tables

1 Limit-load comparisons for out-of-plane moment loads on the branch $\ldots \ldots \ldots \ldots \ldots \ldots \ldots$ 
2 Limit-load comparisons for in-plane moment loads on the branch $\ldots \ldots \ldots \ldots \ldots \ldots \ldots \ldots \ldots$

3 Summary of limit-load ratios for moment loads on the branch $\ldots \ldots \ldots \ldots \ldots \ldots \ldots \ldots \ldots \ldots \ldots$

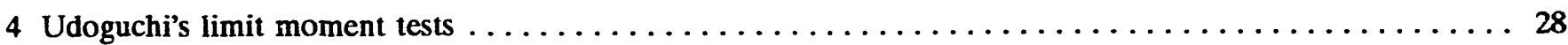

5 Limit moment ratios from corresponding pairs of test specimens from Udoguchi's

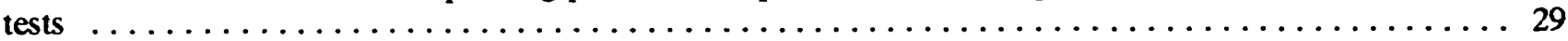

6 Limit loads for combined out-of-plane and torsional moments $\ldots \ldots \ldots \ldots \ldots \ldots \ldots \ldots \ldots \ldots \ldots$

7 Comparisons between WRC-297 stresses set equal to $S_{y}$ and limit load tests $\ldots \ldots \ldots \ldots \ldots \ldots \ldots$

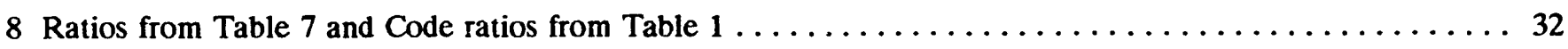

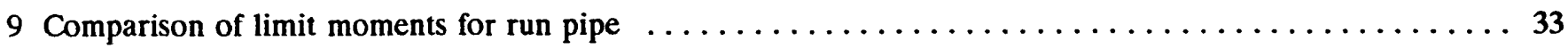

10 Internal pressure effect from corresponding pairs tested with and without

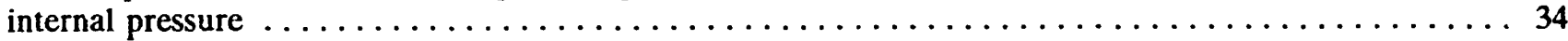

11 Comparison of interaction effects by Code Class 1 piping rules and by separate

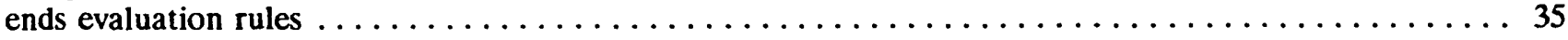

12 Comparison of interaction effects by Class 1 piping rules with AWS (1982) Rules, Fig. 4e moment ratios 


\section{Nomenclature}

$B_{1} \quad$ primary load stress index for internal pressure

$\mathrm{B}_{2 \mathrm{~b}} \quad$ primary load stress index for moments on branch

$B_{2 r} \quad$ primary load stress index for moments through run

$\mathrm{C}_{2 \mathrm{~b}} \quad$ primary plus secondary stress index for moments on branch

$\mathrm{C}_{2 \mathrm{r}} \quad$ primary plus secondary stress index for moments through run

D run pipe diameter (may be outside or mean), see Fig. 1

d branch pipe diameter (may be outside or mean), see Fig. 1

M bending moment

$\mathrm{M}_{\mathrm{Ab}} \quad$ moment applied to branch due to weight and other sustained loads

$\mathrm{M}_{\mathrm{Ar}} \quad$ moment applied to run due to weight and other sustained loads

$\mathrm{M}_{\mathrm{b}} \quad$ moment applied to branch

$\mathrm{M}_{\mathrm{Bb}} \quad$ moment applied to branch due to occasional loads, transients and earthquakes

$\mathrm{M}_{\mathrm{Br}} \quad$ moment applied to run due to occasional loads, transients and earthquakes

$M_{c} \quad$ Code allowable branch moment with an allowable stress of $S_{y}$

$M_{c}^{*} \quad M_{c} / N_{b} ;$ normalized value for $M_{c}$

$M_{r} \quad$ moment applied thru run

$M_{r b} \quad M_{r} / M_{b}$

$\mathrm{M}_{\mathrm{t}} \quad$ test limit moment

$M_{t}^{*} \quad M_{t} / N_{b} ;$ normalized value for $M_{t}$

$\mathrm{M}_{u} \quad$ Billington's limit moment

$\mathrm{M}_{\mathrm{ui}} \quad$ Billington's limit-load for an in-plane branch moment, see Eq. 9

$M_{u i}{ }^{*} \quad M_{u i} / N_{b} ;$ normalized value for $M_{u i}$, see Eq. 10

$M_{\text {мо }} \quad$ Billington's limit-load for an out-of-plane branch moment, see Eq. 6

$M_{\mathrm{uo}}^{*} \quad \mathrm{M}_{\mathrm{uo}} / \mathrm{N}_{\mathrm{b}} ;$ normalized value for $\mathrm{M}_{\mathrm{uo}}$, see Eq. 8

$\mathrm{m}, \mathrm{n} \quad$ normalized bending or membrane stress resultants obtained from design graphs given in WRC-297 as functions of $(D / T),(d / D)$, and $(t / T)$ 


\begin{tabular}{|c|c|}
\hline $\mathbf{M}^{\prime}$ & moment corresponding to elastic stress of $S_{y}$ \\
\hline $\mathbf{N}_{\mathrm{b}}$ & $\left(d^{2} t S_{y}\right)$; theoreticai bending limit-load of branch pipe \\
\hline $\mathrm{P}$ & pressure \\
\hline $\mathrm{Q}_{\mathrm{r}}$ & coefficient used in AWS welding code, see Eq. 26 \\
\hline$Q_{\beta}$ & coefficient used in AWS welding code, see Eq. 25 \\
\hline $\mathbf{R}$ & $\mathrm{D} / 2$ \\
\hline $\mathbf{r}$ & $\mathrm{d} / 2$ \\
\hline$r_{p}$ & nozzle outside radius, see Fig. 1 \\
\hline$S, S_{h}$ & Code allowable stress, Class 2 or 3 piping \\
\hline$S_{\mathrm{m}}$ & Code allowable stress intensity, Class 1 piping \\
\hline$S_{y}$ & yield strength \\
\hline $\mathrm{T}$ & run pipe wall thickness (or torsional moment) \\
\hline $\mathrm{t}$ & branch pipe wall thickness \\
\hline$t_{n}$ & nozzle thickness, see Fig. 1 \\
\hline W & axial load on branch pipe, see Fig. 1 \\
\hline $\mathrm{Z}_{\mathrm{b}}$ & section modulus of branch pipe \\
\hline $\mathrm{Z}_{\mathrm{br}}$ & $\mathrm{Z}_{\mathrm{b}} / \mathrm{Z}_{\mathrm{r}}$ \\
\hline $\mathrm{Z}_{\mathrm{r}}$ & section modulus of run pipe \\
\hline$\beta$ & $\mathbf{r} / \mathbf{R}$; branch-to-run radius ratio \\
\hline
\end{tabular}




\section{Introduction}

This report is essentially a review of the American Society of Mechanical Engineers (ASME) Code', criteria for controlling primary loads in nuclear piping branch connections as expressed by NB-3650 and NB-3683 for Class 1 piping

$$
B_{1} \frac{P D_{o}}{2 T}+B_{2 b} \frac{M_{b}}{Z_{b}}+B_{2 r} \frac{M_{r}}{Z_{r}} \leq \alpha,
$$

and NC/ND-3650 for Class $2 / 3$ piping

$$
\begin{gathered}
B_{1} \frac{P D_{o}}{2 T}+B_{2 b} \frac{M_{A b}}{Z_{b}}+ \\
B_{2 r} \frac{M_{A r}}{Z_{r}} \leq 1.5 S_{h}, \\
B_{1} \frac{P_{\max } D_{o}}{2 T}+B_{2 b}\left(\frac{M_{A b}+M_{B b}}{Z_{b}}\right)+ \\
B_{2 r}\left(\frac{M_{A r}+M_{B r}}{Z_{r}}\right) \leq \beta .
\end{gathered}
$$

The primary load stress indices $B_{1}, B_{2 b}$, and $B_{2 r}$ are given in NB-3683 for both Class 1 and Class $2 / 3$ application. Different values for the stress limits $\alpha, \beta$ are specified in the Code for the four different service level design conditions as follows:

Service Stress Limit $\alpha$ Class $2 / 3$ limit $\beta$ level

\begin{tabular}{lcl} 
Design & & \\
A & $1.5 \mathrm{~S}_{\mathrm{m}}$ & \\
\cline { 3 - 3 } $\mathrm{B}$ & $1.8 \mathrm{~S}_{\mathrm{m}} \leq 1.5 \mathrm{~S}_{\mathrm{y}}$ & $1.8 \mathrm{~S}_{\mathrm{h}} \leq 1.5 \mathrm{~S}_{\mathrm{y}}$ \\
$\mathrm{C}$ & $2.25 \mathrm{~S}_{\mathrm{m}} \leq 1.8 \mathrm{~S}_{\mathrm{y}}$ & $2.25 \mathrm{~S}_{\mathrm{h}} \leq 1.8 \mathrm{~S}_{\mathrm{y}}$ \\
$D$ & $3.0 \mathrm{~S}_{\mathrm{m}} \leq 2.0 \mathrm{~S}_{\mathrm{y}}$ & $3.0 \mathrm{~S}_{\mathrm{h}} \leq 2.0 \mathrm{~S}_{\mathrm{y}}$
\end{tabular}

- The terms Code or ASME Code, as used here, refer to Section III of the ASME Boiler and Pressure Vessel Code, Nuclear Power Plant Components. Paragraphs, equations, and figures from the Code are identified according to the Code numbering scheme.
When these limits are used for design, $S_{y}$ is the Code specified minimum yield strength. For evaluation of criteria, however, $S_{y}$ should be the actual yield strength of the material.

Equations 1-3 and the Code assigned primary load stress indices are intended to control the amount of gross plastic deformation for both static and dynamic loadings. The background and development of the current (1987) stress indices were discussed in detail ty Rodabaugh and Moore (1978). Partly as a result of that study, the Code adopted Eqs. 2 and 3 for Class 2/3 design in 1980 (Moore and Rodabaugh, 1982). As a consequence, a need exists to extend the B stress indices to cover branch connections with $\mathrm{d} / \mathrm{D}>0.5$ because the Class 1 restriction on $d / D$ to values less than 0.5 [NB-3683.8(a)(3)] does not apply to Class $2 / 3$ branch connections.

The major purposes of this report are to collect the available data and to reexamine Eqs. 1-3, including each of the stress indices, in light of new information and the need for an extended $d / D$ parameter range. However, it is not our intent to develop proposed Code rule changes in this study; but, rather to determine whether sufficient information now exists to develop the needed revisions or to determine what additional work needs to be, done to support such an effort.

Each term in Eq. 1 is examined separately in Sections 2-4; the branch moment term $B_{2 b} M_{b} / Z_{b}$ in Section 2, the run moment term $B_{2 r} M_{r} / Z_{r}$ in Section 3, and the pressure term $B_{1} P D_{o} / 2 T$ in Section 4. Combined branch and run moment loadings are discussed in Section 5, and axial loads are discussed in Section 6. Primary load stress indices for Class 2 and 3 branch connections are discussed in Section 7. An overall summary and our recommendations for the additional needed work are given in Section 8. Because most of the available data are for moment loadings on the branch, the $B_{2 b} M_{b} / Z_{b}$ term of Eq. 1 is discussed first. 


\section{The $B_{20} M_{b} / Z_{b}$ Term}

\subsection{Test Data On Branch Bending Moments}

Tables 1 and 2 summarize the available data for outcf-plane moment and in-plane moment loadings, respectively, from the following references: Schroeder (1984)(1978)(1974), Ellyin (1977)(1976), and Rodabaugh (1980). Except for the data collected by Rodabaugh, all the data were obtained from experimental studies sponsored by the Pressure Vessel Research Committee (PVRC). Rodabaugh's data includes a substantial amount of tubular joint data that were used by Billington (1982) in developing design equations for offshore drilling platforms for the petroleum industry.

The test results given in Tables 1 and 2 are normalized to the theoretical bending limit-load of the branch pipe i.e. $M_{t}^{*}=M_{l} /\left(d^{2} t S_{y}\right)$ where $S_{y}$ is the actual yield strength of the pipe material, in order to indicate the relative strength of the branch connection with respect to the branch pipe. The experimental limit-moments $M_{t}$ are those cited by the authors of the abo:e references. In Schroeder's and Ellyin's papers, $M_{t}$ is generally defined at the intersection of a line tangent to the plastic response portion of a loaddisplacement curve and the extrapolated elastic response portion. The limit moments thus obtained usually agree reasonably well with limit moments obtained, according to the Code procedure of Appendix-II, Paragraph II-1430. They are also usually somewhat less than the maximum plastic collapse moments. $M_{t}$ is defined by Rodabaugh as the maximum moment, except in cases where failure occurred before the load-displacement curve reached a horizontal "maximum." For additional information see page 9 of Rociabaugh's (1980) paper.

Code allowable moments are indicated in Tables 1 and 2 by $M_{c}^{*}$ and the ratio $M_{c} / M_{t}$ where $M_{c}$ is the Code allowable moment with an allowable stress of $S_{y}$ and

$$
M_{c}^{*}=M_{c} /\left(d^{2} t S_{y}\right)=(\pi / 4) / B_{2 b},
$$

where the Code stress ificex $B_{2 b}$ is defined as

$$
\begin{gathered}
B_{2 b}=0.5 C_{2 b}= \\
1.5(R / T)^{2 / 3}(r / R)^{1 / 2}(t / T)\left(r / r_{p}\right) \geq 1.0 .
\end{gathered}
$$

The ratio $M_{c} M_{t}$ is, thus, a direct indication of the Code allowable primary load relative to the experimental limit-load if the Code allowable stress were $S_{y}$ A value of $M_{c} / M_{t}=1.0$ would indicate that the permissible design load is exactly equal to the experimental value. Ratios less than 1.0 indicate the amount of conservatism in the Code equation for $B_{2 b}$ for a moment only load.

The $\mathrm{C}_{2 \mathrm{~b}}$ stress index is intended to represent the maximum primary-plus-secondary stress intensity due to moments applied to the branch pipe. The basis for the $C_{2 b}$ index is discussed by Rodabaugh (1970), and Rodabaugh and Moore (1979). It appears to give reasonably accurate results within its intended range of application; i.e., for $D / T \leq 100$ and $d / D \leq 0.5$. These restrictions are in the Code.

In the 1974 Edition of the Code, $B_{2 b}$ was specified as equal to $0.75 C_{2 b}$ rather than the present value of 0.50 $\mathrm{C}_{20}$. The basis fe; the $\mathbf{0 . 7 5}$ factor was as follows. Consider an elbow with an in-plane moment loading. When $C_{2}$ is greater than 2, the maximum stress is largely a thru-the-wall bending stress because the membrane stress at the highest-stressed location is relatively small. In order to develop large plastic deformations, the load must be further increased by a factor of about 1.5 to produce thru-the-wall yielding. This would suggest that $B_{2}=C_{2} / 1.5=0.67 C_{2}$. However, the membrane stress is not exactly zero at the point of maximum bending stress. In view of the absence of appropriate limit moment data or theory at that time $(-1972)$, the relationship $B_{2}=0.75 C_{2}$ was adopted. This same concept was judged to be applicable to branch connections as well; i.e., conservative for design, giving $B_{2 b}=0.75 C_{2 b}$. Rodabaugh and Moore (1978) discuss the basis for changing to $\mathrm{B}_{2 \mathrm{~b}}=0.50 \mathrm{C}_{2 \mathrm{~b}}$.

The data in Tables 1 and 2 seem to indicate that a further decrease in the $B_{2 b}$ index is desirable, perhaps to $B_{2 b}=0.25 C_{2 b} \geq 1.0$. In thinking about reducing $B_{2 b}$, however, it should be recognized that the Code primary stress limits of Eqs. 1-3 can be up to twice the yield stress $\left(2 S_{y}\right)$ for Service Level $D$. If we wanted to make $B_{2 b}=0.25 C_{2 b}$, and defend that change by remaining below the experimental static 


\section{The $\mathrm{B}_{2 b} \mathrm{M}_{b} \mathrm{Z}_{\mathrm{b}}$ Term}

limit moments of Tables 1 and $2^{\circ}$, then, there should be no value of $M_{d} M_{2}$ greater than 0.5 . There are five tests, however, where $\mathrm{M}_{d} \mathrm{M}_{t}$ exceeds 0.5 ; all in Table 1 for out-of-plane moments. Those data are for models S2 and S3 tested by Schroeder (1984), T32 iested by Schroeder (1978), and models (70 - 0.2) and (100 $0.4)$ cited by Rodabaugh (1980). All five models were relatively thin-walled. This association of relatively high $M_{\delta} M_{1}$ ratios with large $D / T$, along with a generally large scatter in the $M_{\delta} M_{t}$ data, leads to the question: Is $\mathrm{B}_{2 \mathrm{~b}}=$ some constant $\mathrm{C}_{2 \mathrm{~b}}$, a good correlation equation? This question is a lead-in to the columns in Tables 1 and 2 headed $M_{w o}{ }^{*}, M_{u o} / M_{t}$ and $M_{\mathrm{ui}}{ }^{*}, \mathrm{M}_{\mathrm{u}} / \mathrm{M}_{\mathrm{t}}$, respectively.

Tables 1 and 2 also include available test data on "tubular joints". These are like branch connections but without a hole in the run pipe. The data are directly relevant to "trunions" used for piping restraints, but also appear to be useful in evaluating limit moments on branch connections. Tubular joint designers are mainly interested in the axial loads on the branch (which, at present, are not considered at all in piping); secondly, in in-plane moment loads; and least of all, in out-of-plane moment loads. Nevertheless, even for out-of-plane moments, Billington (1982) has developed a correlation equation. His limitmoment equation for an out-of-plane moment is given by Eq. 8 of his paper:

$$
M_{u o}=[1.4+9.8(d / D)] Q_{\beta}^{\prime} S_{y} T^{2} d,
$$

where

$$
\begin{gathered}
Q_{\beta}^{\prime}=0.3 /(d / D)[1-0.833(d / D)], \text { for } d / D>0.6 . \\
Q_{\beta}^{\prime}=1.00 \text { for } d / D \leq 0.6 .
\end{gathered}
$$

The normalized value, $\mathrm{M}_{\mathrm{uo}}{ }^{*}$, given in Table 1 is

$$
\begin{gathered}
M_{u o}=M_{u o} /\left(d^{2} t S_{y}\right) \\
=[1.4+9.8(d / D)] Q_{\beta}^{\prime} /[(D / T)(d / D)(t / T)] .
\end{gathered}
$$

The range of application is given as $35 \leq \mathrm{D} / \mathrm{T} \leq 96$; $0.19 \leq(\mathrm{d} / \mathrm{D}) \leq 0.9$.

\footnotetext{
- Recent dynamic, earthquake-like, data indicate that the static limit moment is unnecessarily restrictive as a design criterion for Level $D$ service. However, no acceptable replacement criterion has yet been developed.
}

For in-plane moment loads, Billington's limit-moment relation [Eq. 7, Billington (1982)] is

$$
\mathrm{M}_{\mathrm{ui}}=6.1(\mathrm{~d} / \mathrm{D})(\mathrm{D} / 2 \mathrm{~T})^{1 / 2} \mathrm{~S}_{\mathrm{y}} \mathrm{T}^{2} \mathrm{~d} \text {. }
$$

The normalized value $M_{u i}{ }^{*}$ given in Table 2 is, thus,

$$
\begin{gathered}
\mathbf{M}_{\mathrm{ui}}^{*}=\mathrm{M}_{\mathrm{ui}} /\left(\mathrm{d}^{2} \mathrm{~S}_{\mathrm{y}}\right) \\
=(6.1 / \sqrt{2}) /\left[(\mathrm{D} / \mathrm{T})^{1 / 2}(\mathrm{t} / \mathrm{T})\right] .
\end{gathered}
$$

The range of application is given as $18 \leq \mathrm{D} / \mathrm{T} \leq 96$; $0.19 \leq \mathrm{d} / \mathrm{D} \leq 1.00$.

The limits of application for Billington's equations are incomplete, however, as evident when Eq. 8 is evaluated for $D / T=35$ and $d / D=t / T=0.19$, thus,

$$
\begin{gathered}
\mathrm{M}_{\mathrm{uo}}^{*}=(1.4+9.8 \times 0.19)(1.000) /(35 \times 0.19 \times 0.19) \\
=2.58 .
\end{gathered}
$$

Obviously, the limit-moment of a tubular joint or a branch connection cannot be 2.6 times the limitmoment of the branch pipe. What is needed is an analogy to the $B_{2 b}$ stress index lower limit of 1.00 . Assuming that such a limit were imposed (which means that values of $\mathrm{M}_{\mathrm{u}}{ }^{*}$ do not exceed 1.00) gives the limit-load ratios summarized in Table. 3 .

It is apparent from Table 3 that, on the average, $M_{u}$ is more accurate than $M_{c}$. The average ratio $M_{\delta} M_{t}$ could be brought in line with the test data by adjusting the $\mathrm{C}_{2 b}$ multiplier. However, as indicated by the last column in Table 3, the $M_{u}$ equations are also more consistent in terms of standard deviation.

There are several points concerning the preceding comparisons which merit a short discussion.

1. In these comparisons, we have used $D$ and $d$ as either outside or mean diameter. Generally, the branch connection data are for mean diameters, and the tubular joint data are for outside diameters. A consistent approach should be used.

2. For simplicity, the $\left(r / r_{p}\right)$-term in Eq. 5 for $B_{2 b}$ has been taken as unity. This is generally a small correction of less than ten percent but should be included ili any further work.

3. We have used equations for $M_{c}$ and $M_{u}$ beyond their intended limits; e.g., $B_{2 b}$ is limited to $d / D$ s 
0.5 and $D / T \leq 100$. See also, the limits for $M_{u}$ discussed earlier.

4. When comparing tubular joint data and the equations for $M_{u}$ with branch connection data, it should be recognized that:

a. They are geometrically different; intuitively, we would expect the limit moments for tubular joints, with no hole in the run pipe, to be a bit higher than for branch connections, which have a hole in the run pipe.

b. Differcini definitions for the experimental "lirnit moment" of a tubular joint and a branch connection are used.

5. Both $M_{u}$ and $M_{c}$ are independent of the branch pipe wall thickness. This is apparent for $M_{u}$ in Eqs. 6 and 9. To see this for $M_{c}$, note that:

$$
M_{c}=Z_{b} S_{y} / B_{2 b} \text {, }
$$

and since $Z_{b}=(\pi / 4) d^{2} t$ and $B_{2 b}$ is proportional to $t$, the $t$ 's cancel out in the calculation of $M_{c}$. However, the limit $B_{2 b} \geq 1.0$ has the effect of including $t$ when $t$ is small. limit moment test data abstracted in Table 4. With respect to evaluation of the test limit moments, there are two problems:

1. The actual material yield strengths for the test specimens are not given. Instead, rated values of $245 \mathrm{MPa}(35,560 \mathrm{psi})$ for carbon steel and $206 \mathrm{MPa}(29,870 \mathrm{psi})$ for stainless steel are given. These rated values apparently are equivalent to the ASME Code specified minimum yield strengths, $35 \mathrm{ksi}$ for SA-106 Grade B carbon steel and $30 \mathrm{ksi}$ for SA-312 Type 304 stainless steel. The specified minimum values should always be less than the actual yield strengths. It is not uncommon, however, for the actual values to be as much as $\mathbf{5 0}$ percent higher than the Code specified minimum. For our evaluations, the effect would be to decrease all the test ratios $M_{t} /\left(d^{2} t S_{y}\right)$ given in Table 4 in direct proportion to the ratio of the actual yield strength to the specified minimum.

2. The test specimens dimensions are not given They are nominally described as " $8 \mathrm{~B} \times 6 \mathrm{~B}$. $\mathrm{d} / \mathrm{D}=$ $0.764^{n}$ and "8Bx4B. $d / D=0.462^{n}$. However, results of calculations given by Udoguchi $(1973$, that involve $\mathrm{D}, \mathrm{T}, \mathrm{d}$, and $\mathrm{t}$ can be used to deduce their values; good agreement is obtained by using the following:

\begin{tabular}{|c|c|c|c|}
\hline Mean & $\begin{array}{l}\mathrm{D} \\
\mathrm{T}\end{array}$ & $\begin{array}{r}208.1 \mathrm{~mm}(8.193 \text { in. }) \\
8.2 \mathrm{~mm}(0.323 \text { in. })\end{array}$ & All Specimens \\
\hline Mean & $\begin{array}{l}\text { d } \\
?\end{array}$ & $\begin{array}{r}158.1 \mathrm{~mm}(6.224 \mathrm{in} .) \\
7.1 \mathrm{~mm}(0.280 \mathrm{in} .)\end{array}$ & XX1X Specimens \\
\hline Mean & $\begin{array}{l}d \\
t\end{array}$ & $\begin{array}{c}94.16 \mathrm{~mm} \text { (3.707 in.) } \\
5.74 \mathrm{~mm} \text { (0.226 in.) }\end{array}$ & XX2X Specimens \\
\hline
\end{tabular}

6. For an in-plane moment, $M_{u i} /\left(d^{2} t S_{y}\right)$ is not a function of $d / D$. However, for an out-of-plane moment, $M_{u d} d\left(d^{2} t S_{y}\right)$ decreases as (d/D) increases to a value of 0.65 , then increases between $(d / D)=$ 0.65 and 1.0 .

\subsection{Udoguchi's Tests}

Udoguchi's (1973) paper consists of 154 pages of detailed test results and evaluations, including the
It might be noted that these are almost equal to $8 \times 6$ or $8 \times 4$ Sch. 40 dimensions, but are enough different so that the above tabulated dimensions were used in the evaluations of Table 4.

There appear to be two types of specimens; XFXX = forged and XWXX = welded. The Udoguchi paper develops $B_{2 b}$ indices from data which, for the welded type connections, are essentially identical to what is calculated using the above tabulated dimensions and 
$r_{\mathrm{v}}=r+t / 2$. From this it is deduced that the W-specintens were like those in Tables 1 and 2; i.e., a branch welded into a run pipe. The $B_{2 b}$-indices for the $F$ (forged) type specimens are smaller than for the $\mathrm{W}$-type specimens. If the difference is solely due to $r_{p}$, then $\mathrm{r} / \mathrm{r}_{\mathrm{p}}=0.85$ for the XFIX specimens and $\mathrm{r} / \mathrm{r}_{\mathrm{p}}=$ 0.83 for the XF2X specimens. This implies that Udoguchi (1973) may have used something like the Bonney Forge Weldolets.

Despite the uncertainties, the data provide a basis for comparison of (a) out-of-plane moments vs torsional moments, (b) forged vs welded constructions, and (c) carbon steel vs austenitic stainless steel materials. If it is assumed that corresponding pairs of test specimens are essentially identical, except for the intended variable (i.e., $M$ vs $T, F$ vs $W, C$ vs $S$ ); then, the paired comparison, shown in Table 5, is valid. These comparisons are briefly discussed below.

\subsubsection{Out-of-Plane vs Torsional Moments}

The average ratio of 1.08 for the $M_{\delta} T$ limit moments in Table 5 suggests that torsional moment loading is essentially as severe as out-of-plane moment loading. This is significant because in the past, the ANSI B31.1 Power Piping Code and the ANSI B31.3 Chemical Plant and Refinery Piping Code have evaluated torsional moments on a nominal torsional stress basis. In contrast, the ASME Code applies $B_{2 b}$ to torsional as well as to bending moments. The ASME Code approach is supported by the average ratio of about 1.0 in Table 5.

\subsubsection{Forged vs Wrought Construction}

The average $F / W$ ratio of 1.16 in Table 5 is in reasonable agreement with the $\left(r / r_{p}\right)$ term that probably was used (see preceding discussion of specimen dimensions); i.e., $1 /\left(r / r_{p}\right)=1 / 0.84=1.19$. This is significant because some design guidance indicates that using a local reinforcement like a Weldolet will greatly increase the moment capacity of a branch connection. The data in Table 5, however, indicate that this is not true and that the $\left(r / r_{p}\right)$ term in Eq. 5 for $B_{2 b}$ is about right.

\subsubsection{Carbon vs Stainless Steel Materials}

The average $\mathrm{C} / \mathrm{S}$ ratio of 2.01 in Table 5 might first be compared with the rated yield strength ratio of
$25 / 21=1.19$. If this were the actual yield strength ratio, then Table 5 indicates that a carbon steel branch connection is significantly stronger than a stainless steel branch connection (after normalizing both to actual material yield strengths). This kind of relative result has been apparent in tests on eltows (Greenstreet, 1978) and straight pipe (Gerber, 1974). Components made of stainless steel material seem to have a lower moment capacity than components made of carbon steel material, even though both materials have the same 0.2 percent yield strength or are normalized to the same yield strength.

\subsubsection{Combined Out-of-Plane Moment and Torsion Tests}

Table 4 contains one additional bit of data not oiherwise available; i.e., the combined out-of-plane and torsion test No. $32,35,38$, and 41 . In these tests, the moment ratio $T / M_{o}$ was always 0.462 . Udoguchi's (1973) paper includes two graphs for each test; the graphs for test 32 are included here as Fig. 2. Using the criteria in II-1430 of the Code, one may obtain two limit loads for each test; one from $M_{o}$ vs 8 and the other from $T$ vs $\theta$. The limit loads and ratios to $M_{o}$ only and T only tests are shown in Table 6.

The Code defines $M_{b}$ as the resultant moment vector

$$
M_{b}=\left(M_{o}^{2}+M_{i}^{2}+T^{2}\right)^{1 / 2}
$$

For the particular test combination of $\mathrm{T}=0.462 \mathrm{M}_{\mathrm{o}}$; $\mathrm{M}_{\mathrm{i}}=0$, Eq. 13 becomes

$$
\begin{aligned}
M_{b} & =M_{o}\left(1+0.462^{2}\right)^{1 / 2} \\
& =1.102 M_{o} .
\end{aligned}
$$

If we assume that the magnitude of the branch moment $M_{b}$, as given by Eq. 13, is fixed at some maximum value as prescribed by Code Eq. 9 , which is Eq. 1 here, then for the particular combined loading case of this test, i.e., $T=0.462 \mathrm{M}_{\mathrm{o}} ; \mathrm{M}_{\mathrm{i}}=0$, the maximum value of $M_{o}$ is limited to 0.907 times the value that would be permitted if $\mathrm{T}$ were absent. Also, the maximum value of $T$ is limited to $(0.907)(0.462)=$ 0.419 times the value that would be permitted if $\mathrm{M}_{\text {o }}$ were absent. These values compared with the average ratios in Table 6 of 0.907 vs 0.98 and 0.419 vs 0.52 indicate that the Code method for combining 
moments is slightly conservative for these particular branch connections.

\subsection{WRC-297 Elastic Stresses}

The availability of Welding Research Council Bulletin No. 297 (Mershon, 1984), is a major motivation for the present review work because it provides data on elastic stresses at branch connections with either outof-plane or in-plane branch moments, $M_{o}$ or $M_{i}$. The Bulletin is judged to be valid for $d / D \leq 0.5$ and $D / T \leq$ 2500. Here, the question is: Do the elastic stresses from WRC-297 provide useful guidance for branch limit moments? Table 7 summarizes a first look at this question.

Table 7 includes those models from Table 1 with d/D $\leq 0.5$; i.e., within the scope of WRC-297 elastic stresses. The total (membrane plus bending) elastic stresses for the run pipe (vessel) is given by:

$$
\sigma=M(6 m+n) / T^{2} d,
$$

where $\mathrm{m}, \mathrm{n}$ are normalized bending or membrane stress resultants obtained from the design graphs given in WRC-297 as functions of $(D / T),(d / D)$, and $(t / T)$. In these examples, we have used design graphs for the circumferential moment, $M_{c}$, which is the out-of-plane moment. Values of $m$ and $n$ are given for both the 9-direction and the r-direction. In Table 7, we have used those directions which give the maximum membrane and total stress in the run pipe.

Setting $\sigma=S_{y}$ and $M=M^{\prime}$ in Eq. 15 gives the membrane and total stress components for the run pipe:

$$
\begin{array}{r}
{\left[\mathrm{M}^{\prime} /\left(\mathrm{d}^{2} \mathrm{t} \mathrm{S}_{\mathrm{y}}\right)\right]_{\mathrm{mem}}=1 /[\mathrm{n}(\mathrm{D} / \mathrm{T})(\mathrm{d} / \mathrm{D})(\mathrm{t} / \mathrm{T})],} \\
{\left[\mathrm{M}^{\prime} /\left(\mathrm{d}^{2} \mathrm{t} \mathrm{S}_{\mathrm{y}}\right)\right]_{\mathrm{tot}}=1 /[(6 \mathrm{~m}+\mathrm{n})(\mathrm{D} / \mathrm{T})(\mathrm{d} / \mathrm{D})(\mathrm{t} / \mathrm{T})] .}
\end{array}
$$

WRC-297 also gives data from which the elastic stresses in the branch pipe can be calculated, thus:

$$
\sigma_{a}=M^{\prime}\left[4 t /(\pi d)+6 m_{r}-3 n_{r}\right] / t^{2} d,
$$

where $m_{r}$ and $n_{r}$ are specifically in the r-direction. Setting $\sigma_{\mathrm{a}}=\mathrm{S}_{\mathrm{y}}$ in Eq. 18 gives the total normalized bending stress in the branch as

$$
=1 /\left[(4 / \pi)+\left(6 m_{r}-3 n_{r}\right)(D / T)(d / D)(T / t)\right] .
$$

It is not expected that the elastic stress ratios, $M^{\prime} /\left(d^{2} t S_{y}\right)$, shown in Table 7 , will be equal to $M_{t} /\left(d^{2} t S_{y}\right)$. Rather, the question is whether there is some constant that, when multiplied by a WRC-297 elastic stress, is a better predictor of limit moments than a constant times $C_{2 b}$, i.e., the $B_{2 b}$ stress index. This would be indicated by a smaller standard deviation than obtained using a constant times $\mathrm{C}_{2 b}$. Tablc 8 shows iatios, averages, and standard deviation/average. This very limited study indicates that the WRC-297 elastic stresses are no better than the $B_{2 b}$ stress index as a predictor of out-of-plane limit moments.

Further investigation of the use of WRC-297 stresses as a predictor of limit loads should be conducted. Consideration should also be given to using the computer program FAST2 (Steele and Steele, 1983) to analyze the models of Table 7 to eliminate the interpolation errors involved in using the WRC-297 design graphs. (Those graphs were developed from data generated by FAST2.)

Because the review work is intended to cover nozzles in vessels, as well as branch connections in piping, the guidance given in NC-3200 for Class 2 vessel nozzles is significant. Tables NC-3321-1 and NC-3321-2 can be interpreted as saying that, for nozzle moments, the only limitations is that the calculated vessel membrane stress must not exceed $\mathrm{S}, 1.1 \mathrm{~S}, 1.5 \mathrm{~S}$, and $2.0 \mathrm{~S}$ for Levels $A, B, C$, and $D$, respectively, where $S=$ allowable stress. For stainless steels at elevated temperatures, $\mathrm{S}=0.9 \mathrm{~S}_{\mathrm{y}}$. Looking at Table 8 under the column headed "membrane", we see that, for Level $D$, this criterion permits moment loads ranging from $(0.9)(2)(0.89)=1.60$ for T31, to $(0.9)(2)(8.40)=$ 15.1 for S3, times the experimental limit loads. The overall average is 4.4 times the actual test values.

It appears that the Code vessel rules, not only for Class 2/3, but also for Class 1 and in Appendix F, have the potential of being grossly unconservative for nozzles in vessels subjected to moment loading. Accordingly, further work should include an evaluation of those rules and recommendations for changes, if appropriate. 


\section{The $B_{22} M_{r} / Z_{r}$ Term}

Figure 1 shows one of the three run moments considered under this heading; the in-plane moment $M_{i}$ applied to one end of the run pipe and reacted by an equal moment at the other end of the run pipe.

\subsection{Available Data}

There are no available data, either experimental or theoretical, on run-pipe limit moments. There is a considerable amount of data on tubular joints with $M$ loading (Rodabaugh, 1980), and in at least some of the tests the failure mode was simply yielding of the run pipe. However, the absence of an opening in the run pipe in such joints would raise major questions concerning the relevance of those data to branch connections.

\subsection{The Code $B_{2 r}$ Stress Index}

For moment loading on the run, the Code gives the primary load stress index as

$$
\begin{gathered}
\mathrm{B}_{2 \mathrm{r}}=0.75 \mathrm{C}_{2 \mathrm{r}}=(0.75)(1.15)\left[(\mathrm{R} / \mathrm{T})(\mathrm{r} / \mathrm{R}) /\left(\mathrm{t}_{\mathrm{n}} / \mathrm{T}\right)\right]^{1 / 4} \\
\geq 1.00 .
\end{gathered}
$$

The basis for $\mathrm{C}_{2 \mathrm{r}}$ is given in Rodabaugh and Moore (1979). Briefly, $C_{2 r}$ is the result of dividing the maximum total stresses obtained from a series of finite element analyses into primary-plus-secondary $\left(\mathrm{C}_{2 \mathrm{r}}\right)$ and peak $\left(\mathrm{K}_{2 \mathrm{r}}\right)$ portions for ASME Code Class 1 fatigue evaluation procedures. Because $\mathrm{K}_{2 \mathrm{r}}$ was assigned a value of 1.75 , the $B_{2 r}$ stress index includes an effective multiplier of $0.75 / 1.75=0.43$ on the maximum elastic stress intensity. This compares with the 0.5 multiplier on $\mathrm{C}_{2 b}$ for $\mathrm{B}_{2 b}$. The run moment stress index $B_{2 r}$ is probably still very conservative, but in the absence of either test data or limit moment theory it has not been decreased.

The quantity in the brackets in Eq. 20 can be simplified to $r / t_{n}$. However, for our purposes it is more informative to keep the dimensional ratios as shown. Note that $t_{n}$ is the nozzle thickness, not the branch pipe thickness. Conceptually, increasing $t_{n}$ reinforces the opening in the run pipe, decreases the value of $B_{2 r}$, and increases the moment capacity of the run pipe. However, if a small hole is considered $(d / D<<1.0)$ in a run pipe, note that $B_{2 r}$ becomes infinite as $t_{n}$ decreases to zero, and the Code allowable moment goes to zero. Intuitively, it seems that for a small hole the value of $t_{n}$ would have little effect on the limit moment capacity of the run pipe. This aspect leads into the seemingly irrelevant subject of limit moments for cracked pipe.

\subsection{Limit Moments of Cracked Pipe}

The intergranular stress corrosion problem has led to extensive research on circumferentially cracked pipe. One part of this work led to the development, and verification by tests, of a limit bending moment equation (Kanninen, 1976).

$$
\mathrm{M}_{\mathrm{cp}}=\mathrm{D}^{2} \mathrm{TS}_{\mathrm{y}}[\cos (\theta / 2)-0.5 \sin \theta] \text {, }
$$

where $\theta=\sin ^{-1}(r / R)$; see Fig. 3 .

The "cracked-pipe" model is deemed defendable as a lower bound for branch connections. Table 9 shows comparisons between Code allowable moments and allowable moments by Eq. 21 . It can be seen that there are some parameters for which the cracked pipe model would permit a significant increase in the allowable moment; e.g., for $R / T=50, t_{n} / T=r / R, r / R$ $=0.05$, the allowable moment would be increased by a factor of 2.9. This suggests the following potential criterion for Code use,

$$
\begin{aligned}
B_{2 r}=\operatorname{Min}\left\{0.75 C_{2 r}\right. & 1 /[\cos (\theta / 2)-0.5 \sin \theta]\} \\
& \geq 1.0 \\
\theta= & \sin ^{-1}(r / R) .
\end{aligned}
$$

However, before Eq. 22 is accepted, the question of torsional moments needs to be addressed. The lower bound on $B_{2 x}$ of 1.00 could be reduced to $(\pi / 4) \sim 0.8$ for bending moments, but, for torsional moments, the limit moment by the maximum shear theory is $(\pi / 4)$ $D^{2}$ TSy. Hence, the lower bound on $B_{2 r}$ of 1.00 is appropriate. The research work on cracked pipe that we have reviewed does not address the question of torsional moments. That question should be addressed as well. 


\section{The $\mathrm{B}_{1} \mathrm{PD}_{\mathrm{o}}$ 2T Term}

First, it should be noted that adequacy of internal pressure design is covered by NB/NC/ND-3640 of the Code. The function of the pressure term in Code Eq. 9, which is Eq. 1 here, is to represent the influence of internal pressure on the moment load capacity.

There is some data on the effect of internal pressure combined with branch moments. In Tables 1 and 2, there are five pairs of tests on nominally identical models, where one was tested with zero internal pressure, and the other was tested with a constant internal pressure. These pairs and the results are shown in Table 10. On the average, internal pressure decreased the limit moments by about 16 percent and, on the average, by about the same amount as indicated by Eq. 1; i.e., by: $1-0.5 \mathrm{PD} /\left(2 \mathrm{TS}_{\mathrm{y}}\right)$.

Udoguchi's (1973) tests given in Table 4, were all run with internal pressure. There is no apparent way to estimate the internal pressure effect from these tests, however, because comparable specimens were not tested without internal pressure. Noting that specimens CW1M and CW2M are carbon steel, presumably dimensioned like the Table 1 models, one might think of comparing these two specimens with the zero pressure tests of Table 1. Unfortunately, the uncertainty concerning Udoguchi's (1973) actual yield strengths would make such comparisons highly

suspect. 


\section{The $B_{2 b} M_{b} / Z_{b}$ and $B_{2 r} M_{r} / Z_{t}$ Combined Terms}

The run moment, $M_{r}$, is always an essential part of piping evaluations but is not normally considered for nuclear power plant vessel designs, although the question of the effect of run moments in high, slender vessels subjected to wind loading sometimes arises.

The ASME Code leaves the evaluation of such vessels, which might have nozzles at locations of high $M_{r} Z_{r}$ stresses, to the discretion of the vessel designer.

Figure 4a shows the Code nomenclature for moments at a Class 1 piping branch connection. The run muments are defined as:

$$
\begin{aligned}
& M_{i r}=0 \text { if } M_{i 1} \text { and } M_{i 2} \text { have the same sign; } \\
& M_{i r}=\text { smaller of } M_{i 1} \text { and } M_{i 2} \text { if } M_{i 1} \text { and } M_{i 2} \text { have } \\
& \text { opposite signs. } \\
& i=x, y, z \text {. }
\end{aligned}
$$

Figure $4 \mathrm{~b}$ shows the moment combination that has been used for most elastic stress and fatigue evaluations. Figure $4 c$ shows the moment combination used in all the limit load tests discussed in the preceding. In both Fig. $4 \mathrm{~b}$ and $4 \mathrm{c}$, the sign of the run moment does not change; hence, by the Code Class 1 rules these are treated as identical loadings; i.e., $M_{b}=M$ and $M_{r}=0$. Obviously, however, they are not really identical loadings.

Figure $4 \mathrm{~b}$ can be defended on the basis that it is a worst case, because all the branch moment is reacted at one end of the run. In contrast, Fig. $4 \mathrm{c}$ might be described as a best case because the branch moment is evenly reacted at both ends of the run. The question arises with respect to any further decrease in $B_{2 b}$ "Could such a reduction be defended in view of the limit load test data from tests like Fig. 4c?".

Intuitively, it would seem that the differences between Fig. 4b and $4 c$ loadings would be small for small $d / D$, where perhaps small $\mathrm{d} / \mathrm{D}$ might be $\sim 0.5$ and less. However, for $\mathrm{d} / \mathrm{D}=1.00$, it would seem that a difference of up to a factor of two might exist. Further work should search for data (test or theoretical data on elastic stresses, test data on fatigue, and test data on limit moments) ${ }^{*}$ that might

*Recent unpublished work by D. G. Moffat at the University of Liverpool includes limit load tests on full outlet models. be relevant to assessing the difference between Fig. $4 \mathrm{~b}$ and $4 \mathrm{c}$ loadings.

Prior to 1980 , the Code ignored any potential interaction between branch and run moments for Class 2 and 3 piping because each of the three ends of the branch connection (or tee) was evaluated separately. The 1980 winter addenda of the Code changed the primary load evaluation criteria for all Class 2 and 3 piping from fatigue based i-factor equations [Code Eqs. 8 and 9] to be like the current Class $1 B_{1}$ and $B_{2}$ stress index equations [which are Eqs. 2 and 3 herein]. At the same time the procedure for evaluating combined branch and run moments effects for Class 2 and 3 branch connections and tees was changed to agree with the Class 1 procedure [NC-3653.3(b)], but only for evaluating primary loads. The "separate" evaluation procedure was left intact for evaluating secondary thermal expansion and nonrepeated anchor movement loads.

It now appears that, although the 1980 Code action was correct for the evaluation of primary loads in general, it may have been incomplete for treating branch connections and tees. A 1983 study on the comparison of fatigue evaluation methods for Class 1 and Class $2 / 3$ piping, Rodabuagh (1983), includes an extensive discussion on the two different methods for evaluating branch and run moment interactions. Pertinent findings from that study are the following:

1. If $M_{r}=0$ by Class 1 rules, the Class 1 and the separate evaluation procedures give the same results.

2. If $Z_{b}=Z_{r}$ and $B_{2 r}=B_{2 b}$, the Class 1 and the separate evaluations give the same results (e.g., an equal branch and run size).

3. For a small branch in a large run, the Class 1 rules are more conservative by a factor of not more than two at a worst case ratio of $Z_{\downarrow} / Z_{r}$.

4. There is no clear evidence that the Class 1 method is any more "correct" than separate evaluations.

To bring the above more into perspective, Table 11 shows the ratios of allowable moments by Class 1 and "separate" evaluation rules for Figs. $4 \mathrm{~d}$ and $4 \mathrm{e}$ moment ratios. These figures illustrate moment loading combinations that might be obtained from a piping system analysis. Like the preceding examples, they are 
in static equilibrium." For Class 1 piping, the Code rules give:

Fig. 4d: $M_{b}=M ; M_{r}=M / 2$,

Fig. 4e: $M_{b}=M ; M_{r}=9 M$.

Table 11 is based on $B_{2 b}=B_{25}$, for that assumption:

$$
\begin{gathered}
M_{c 2} / M_{c 1}=\operatorname{Min}\left\{1+Z_{b r} M_{r b}\right) ; \\
\left.\left[\left(1+Z_{b r} M_{c t}\right) / Z_{b r}\left(M_{c b}+1\right)\right]\right\}
\end{gathered}
$$

where

$$
\begin{aligned}
& \mathrm{Z}_{\mathrm{br}}=\left(\mathrm{Z}_{\sqrt{ }} \mathrm{Z}_{\mathrm{r}}\right), \\
& \mathrm{M}_{\mathrm{rb}}=\left(\mathrm{M}_{\mathrm{r}} \mathrm{M}_{\mathrm{b}}\right) \text {, } \\
& \mathrm{M}_{\mathrm{c} 2}=\text { allowable branch momint by Code Class } 2 / 3 \\
& \text { rules } \\
& \mathrm{M}_{\mathrm{c} 1}=\text { allowable branch moment by Code Class } 1 \\
& \text { rules }
\end{aligned}
$$

Eqs. 5 and 20 give $B_{2 b} / B_{2 x}$ ratios that are not unity. As indicated by Tables 1 and 2 , the branch stress index $B_{2 b}$ is very inaccurate; possibly $B_{2 r}$ is even more inaccurate, particularly for $\mathrm{d} / \mathrm{D}>0.5$. Accordingly, using $B_{20} / B_{2 \pi}=1.00$ as the basis for Table 11 is not necessarily less accurate than using $B_{20} B_{2 x}$ from Eqs. 5 and 20.

There are also tactical advantages in using the separate evaluation procedure, however. For example, in the design process, large or complicated piping systems are often divided at branch connections for system analysis purposes. Using the Class 1 procedure, it is then necessary to examine the results from the files of two separate systems to determine Code compliance. This extra complication is not necessary with the separate evaluation procedure. In addition, the loss of earthquake moment signs from a dynamic modal analysis and the resulting uncertainties introduced into the Class 1 procedure would cease to be a problem. Accordingly, it appears that serious consideration should be given to revising the Code to permit the use of the separate evaluation procedure for both Class 1 and Class $2 / 3$ primary load evaluations for branch connections and tees.

\footnotetext{
-In a modal dynamic analysis (e.g., for earthquakes), static equilibrium exists on a mode-by-mode basis because the branch connection is represented by a point mass which, of course, has no rotary inertia. However, it is recognized that in usual piping system modal analyses, the combination of modes loses the signs of the moments.
}

Some precedent and guidance on interaction between run moments and branch moments is contained in the structural welding code AWS D1.1 (1982), in paragraph 10.5 , "Limitations of the Strength of Welded Tubular Connections." For T-connections in circular cross section tubing with moment loadings on run and branch, the design guidance is:

$$
(t / T)\left(M_{b} / Z_{b}\right) \leq Q_{B} Q_{S} S_{y} /\left[0.9(R / T)^{0.7}\right]
$$

where

$$
\begin{gathered}
Q_{\beta}=0.3 /[\beta(1-0.833 \beta)] \text { for } \beta>0.60, \\
=1.00 \quad \text { for } \beta<0.60, \\
\beta=r / R ; \\
Q_{f}=1.22-0.5 U \text { for } U>0.44 ， \\
=1.00 \quad \text { for } U<0.44 ; \\
U=M_{r} /\left(0.6 Z_{r} S_{y}\right) .
\end{gathered}
$$

Table 12 shows the interaction effect for various sized branch connections in a 24 NPS pipe according to the Code rules and the AWS rules for the particular moment ratios shown in Fig. 4; $M$ is the allowable moment with $M_{r}=9 M_{b}$ for the Code rules and $M_{r}=$ $10 \mathrm{M}_{b}$ for the AWS rules; $M_{o}$ is the allowable moment with $M_{r}=0$. The ratio $M / M_{o}$ for the Code rules is given by

$$
\begin{gathered}
M / M_{o}(\text { Code })= \\
\left.B_{2 b} / B_{2 b}+B_{2 r}\left(Z_{b} / Z_{r}\right)\left(M_{r} / M_{b}\right)\right],
\end{gathered}
$$

with $\left(M_{r} / M_{b}\right)=9, B_{2 b}$ from Eq. 5, and $B_{2 r}$ from Eq. 20. The ratio $M / M_{0}$ under the $A W S$ rules is given by

$$
\begin{gathered}
M / M_{\circ}(A W S)= \\
1.22 /\left[1+0.5 C_{o}\left(Z_{b} / Z_{r}\right)\left(M_{r} / M_{b}\right) / 0.6\right] \leq 1.000
\end{gathered}
$$

with $\left(M_{r} M_{b}\right)=10$, and

$$
C_{o}=Q_{B} /\left[0.9(R / T)^{0.7}(t / T)\right] \text {. }
$$

While the AWS rules are probably relevant to maximum combinations of branch and run moments acting on tubular joints, their relevance to combinations of branch and run moments on branch connections is questionable. This shows up by using 
Eq. 24 to determine an allowable run moment $M_{r}$ for $M_{b}=0$. Then, $Q_{f}=0$ and

$$
\mathrm{M}_{\mathrm{r}} /\left(\mathrm{D}^{2} \mathrm{TS}_{\mathrm{y}}\right)=(\pi / 4)(1.22)(0.6) /(0.5)=1.15 \text {. }
$$

That $M_{r} /\left(D^{2} T S_{y}\right)$ is about equal to unity is perhaps appropriate for a tubular joint where there is no opening in the run pipe. But, what is the throughthe-run in-plane moment limit for a $24 \times 24$ Sch. 40 branch connection? Equation 21 suggests that $\mathrm{M}_{r} /\left(\mathrm{D}^{2} \mathrm{TS}_{\mathrm{y}}\right)$ could be around 0.2 for a thin branch wall. At present, there is not an answer to this question.

The preceding discussion concerning Tables 11 and 12 is included, in part, to emphasize the large uncertainties in evaluating the effects of combined moments. The reader should consider this discussion when reading Section 7.1. 


\section{Axial Loads in the Branch Pipe}

Figure 1 shows an axial load, W, which is not considered in piping system evaluations of branch connections but is considered for pressure vessel nozzles. Accordingly, consideration of W-loads should be included in further evaluations for limit loads.

We are not aware of any axial limit load (W) tests on either branch connections or nozzles in vessels. However, many such tests have been run on T-tubular joints; for example, Rodabaugh (1980), abstracts 71 such tests. Since 1980 , more data have probably become available; e.g., in Offshore Technology Conference papers of 1980-1987. WRC-297 gives data from which elastic stresses due to W-loads can be calculated. The AWS Code (1982) gives design guidance for W-loads. 


\section{B Indices for Class 2/3 Piping Branch Connections}

With the introduction of B indices for Code Class 2 piping, the need exists to provide $B$ indices for branch connections not covered by the Class 1 design rules.

\section{$7.1 \mathrm{~d} / \mathrm{D}>0.5$}

Class 1 branch connections are limited to $d / D \leq 0.5$.

In Class $2 / 3$ piping, branch connections with $d / D$ up to 1.0 are permitted and are occasionally used. A fair amount of branch moment data are available for $\mathrm{d} / \mathrm{D}>0.5$ (see Tables 1,2 , and 4 ) but, there are no comparable data for run moments.

\subsection{Pad Reinforcement}

A pad reinforcement consists of an annular ring, with I.D. equal to $d+$ welding clearance, O.D. of about $2 d$, and thickness of about $T$, shaped to fit the surface of the run which is welded to the branch pipe and run pipe on the inner edge and welded to the run pipe at the outer edge. These are non-integral

reinforcements. They are not permitted in Class 1 piping but are permitted, and are used fairly often, in Class $2 / 3$ piping. There are very few data for this type of reinforcement. Further work should discuss and develop B-indices for pad reinforced branch connections. 


\section{Summary and Recommendations}

With respect to the original objectives of this study, it has been determined that a real need exists to revise the present Code criteria for evaluating primary loads on both Class 1 and Class $2 / 3$ piping branch connections (and tees). The present usage of the $B_{1}$, $B_{2 b}$, and $B_{2 r}$ stress indices in the criteria equations, Eqs. 1-3 herein, should be continued. However, the rather complex treatment of combined branch and run moments, i.e., NB-3683.1(d) for Class 1 and NC/ND3653.3(b) for Class $2 \beta$, is not supported by available information. Therefore, it is recommended that this combined loading evaluation procedure be replaced for primary loads by the separate leg evaluation procedure specified in NC/ND-3653.3(c) and NC/ND36533.3(d). However, it is not recommended that similar action be taken for fatigue and/or secondary load evaluations of Class 1 piping. Further work should be undertaken on the development of better criteria for the treatment of combined branch and run moment effects.

This report also suggests that the $B_{2 b}$ stress index might be reducible by a factor of 2 and the $B_{2 r}$ stress index might be reducible by a factor of up to 3 . Additional work needs to be done, however, in support of specific Code revisions. Further work should include the following:

1. Continue the investigation of the use of WRC-297 elastic stresses as a predictor of limit moments. As part of that investigation, the computer program FAST2 (Steele and Steele, 1983) should be used to analyze the test models listed in Table 7.

2. Review the Code vessel rules (Classes 1,2 and 3, and Appendix F) for adequacy in predicting limit loads.

3. Develop a limit load theory for circumferentially cracked pipe subjected to torsional moments as a potential model for run-pipe torsional moments.

4. Search for data (experimental or theoretical elastic stresses, test data on fatigue, test data on limit moments) which would be relevant for assessing the difference between Figs. $4 \mathrm{~b}$ and $4 \mathrm{c}$ loadings.

5. Conduct further studies of the AWS rules for tubular connections, particularly with respect to interaction between branch and run moments.
6. Develop simple design guidance for evaluation of branch axial limit loads; W-loads in Fig. 1.

7. Develop B-indices for Class $2 / 3$ branch connections for $d / D$ up to 1.0 and for branch connections with pad reinforcement.

The overall objective of this additional effort should be to develop simple, realistic design guidance for limit loads and to recommend appropriate changes to Code Eq. 9 and its B stress indices. 


\section{References}

ANSI/AWS D1.1-82, "Structural Welding Code," 6th ed., American Welding Society, 550 North LeJuene Rd., Miami, FL 33126, January 1, 1982.

ASME Boiler and Pressure Vessel Code, Nuclear Power Plant Components, Sectiun III - Div. 1, 1986 edition, ASME, New York.

Billington, C. J., et al., "Background to New Formulae for the Ultimate Limit State of Tubular Joints," Paper No. OTC 4189, Offshore Technology Conference, Houston, TX, May 1982.

Ellyin, F., "Experimen'al Investigation of Limit Loads of Nozzles in Cylindrical Vessels," WRC Bulletin 219, September 1976.

Ellyin, F., "An Experimental Study of Elasto-Plastic Response of Branch-Pipe Tee Connections Subjected to Internal Pressure, External Couplas and Combined Loadings," WRC Bulletin 230, September 1977.

Gerber, T. L., "Plastic Deformation of Piping Due to Pipe-Whip Loading," ASME Paper No. 74-NE-1, Presented at ASME Joint Conference, Pressure Vessels and Piping Division aid Nuclear Materials Division, Miami Beach, FL, June 1974.

Greenstreet, W. L., "Experimental Study of Plastic Responses of Pipe Elbows," ORNL/NUREG-24, Oak Ridge National Laboratory, February 1978.

Kanninen, M. F., et al., "Mechanical Fracture Predictions for Sensitized Stainless Steci Piping with Circumferential Cracks," EPRI NP-192, September 1976.

Mershon, J. L., et al., "Local Stresses in Cylindrical Shells Due to External Loadings on Nozzles Supplement to WRC Bulletin No. 107," WRC Bulletin 297, New York, August 1984.

Moore, S. E. and Rodabaugh, E. C., "Background for Changes in the 1981 Edition of the ASME Nuclear Power Plant Components Code for Controlling Primary Loads in Piping Systems," J. Press. Vessel Tech., ASME Trans. 104: 351-61, November 1982.

Rodabaugh, E. C., "Comparisons of ASME Code Fatigue Evaluation Methods for Nuclear Class 1 Piping with Class 2 or 3 Piping," NUREG/CR-3243
(ORNL/Sub/82-22252/1), Oak Ridge National Laboratory, June 1983.

Rodabaugh, E. C., "Review of Data Relevant to Design of Tubular Joints for Use in Fixed Offshore Platforms," WRC Bulletin 256, January 1980.

Rodabaugh, E. C., "Stress Indices for Small Branch Connections with External Loadings," ORNL-TM3014, Oak Ridge National Laboratory, August 1970.

Rodabaugh, E. C. and Moore, S. E., "Evaluation of the Plastic Characteristics of Piping Products in Relation to ASME Code Criteria," NUREG/CR-0261 (ORNL/Sub-2913/8), Oak Ridge National Laboratory, July 1978.

Rodabaugh, E. C. and Moore, S. E., "Stress Indices and Flexibility Factors for Nozzles in Pressure Vessels and Piping," NUREG/CR-0778 (ORNL/Sub-2913/10), Oak Ridge National Laboratory, June 1979.

Schroeder, J., et al., "Analysis of Test Data on Branch Connections Exposed to Internal Pressure and/or External Couples," WRC Bulletin 200, November 1974.

Schroeder, J., "Large Cylindrical Vessels Loaded on Nozzles," Unpublished progress report to PVRC S/C ROEL, January 13, 1984.

Schroeder, J. and Tugcu, P., "Plastic Stability of Pipes and Tees Exposed to External Couples," WRC Bulletin 238, June 1978.

Steele, C. R. and Steele, M. L., "Stress Analysis of Nozzles in Cylindrical Vessels with External Load," J. Pressure Vessel Technology, Transaction of ASME 105, 191-200, August 1983.

Udoguchi, T., "Experimental Study on Limit Design for Nuclear Power Plant Facilities During Earthquakes, 1973," JPNRSR-5, Translation by USNRC, Available from USERDA Technical Information Center, Oak Ridge, TN 37830. 
Table 1. Limit-load comparisons for out-of-plane moment loads on the branch

\begin{tabular}{|c|c|c|c|c|c|c|c|c|c|}
\hline \multirow{2}{*}{$\begin{array}{l}\text { Data source } \\
\text { reference }\end{array}$} & \multirow{2}{*}{$\begin{array}{l}\text { Model } \\
\text { Number }\end{array}$} & \multicolumn{3}{|c|}{ Dimensional parameters } & \multicolumn{3}{|c|}{ Normalized limit load } & \multicolumn{2}{|c|}{ Limit-load ratio } \\
\hline & & $\mathrm{D} / \mathrm{T}$ & $d / D$ & $\mathbf{V}$ & $\mathbf{M}_{\mathbf{i}}^{*}$ & $\mathbf{M}_{c}^{*}$ & $M_{\infty}{ }^{*}$ & $\mathbf{M}_{\mathbf{S}} \mathbf{M}_{\mathbf{t}}$ & $\mathbf{M}_{\text {ud }} / \mathbf{M}_{\mathbf{t}}$ \\
\hline $\begin{array}{c}\text { Schroeder } \\
\text { (1974) }\end{array}$ & $\begin{array}{l}\text { T4 } \\
\text { T10 } \\
\text { T6 } \\
\text { T16 } \\
\text { T13 }\end{array}$ & $\begin{array}{l}25 \\
34.5 \\
25 \\
42 \\
34.5\end{array}$ & $\begin{array}{l}0.5 \\
0.7 \\
1.0 \\
1.0 \\
0.7\end{array}$ & $\begin{array}{l}0.50 \\
1.27 \\
1.00 \\
1.00 \\
1.27\end{array}$ & $\begin{array}{l}0.72 \\
0.48 \\
0.59 \\
0.49 \\
0.32\end{array}$ & $\begin{array}{l}0.275 \\
0.0738 \\
0.0972 \\
0.0688 \\
0.0738\end{array}$ & $\begin{array}{l}1.008 \\
0.277 \\
0.806 \\
0.480 \\
0.277\end{array}$ & $\begin{array}{l}0.38 \\
0.15 \\
0.16 \\
0.14 \\
0.23\end{array}$ & $\begin{array}{l}{ }^{b} 1.4 \\
0.58 \\
1.37 \\
0.98 \\
0.87\end{array}$ \\
\hline $\begin{array}{c}\text { Schroeder } \\
(1978)\end{array}$ & $\begin{array}{l}\text { T18 } \\
\text { T20 } \\
\text { T21 } \\
\text { T22 } \\
\text { T23 } \\
\text { T24 } \\
\text { T25 } \\
\text { T29 } \\
\text { T28 } \\
\text { T27 } \\
\text { T26 } \\
\text { T33 } \\
\text { T34 } \\
\text { T30 } \\
\text { T31 } \\
\text { T32 }\end{array}$ & $\begin{array}{l}34.5 \\
34.5 \\
34.5 \\
34.5 \\
25 \\
34.7 \\
35 \\
45 \\
45 \\
45 \\
45 \\
25 \\
25 \\
45 \\
45 \\
34.5\end{array}$ & $\begin{array}{l}0.4 \\
0.6 \\
0.3 \\
0.8 \\
0.7 \\
0.2 \\
0.97 \\
0.4 \\
0.6 \\
0.8 \\
0.96 \\
0.4 \\
0.6 \\
0.2 \\
0.3 \\
0.5\end{array}$ & $\begin{array}{l}0.80 \\
1.20 \\
0.60 \\
1.60 \\
0.70 \\
0.40 \\
1.94 \\
1.33 \\
2.00 \\
2.67 \\
3.20 \\
0.4 \\
0.6 \\
0.67 \\
0.9 \\
0.5\end{array}$ & $\begin{array}{l}0.5 ? \\
0.16 \\
0.75 \\
0.33 \\
0.70 \\
0.90 \\
0.27 \\
0.33 \\
0.22 \\
0.16 \\
0.17 \\
1.00 \\
0.77 \\
1.10 \\
0.62 \\
0.41\end{array}$ & $\begin{array}{l}0.155 \\
0.0844 \\
0.239 \\
0.0548 \\
0.166 \\
0.437 \\
0.0407 \\
0.0781 \\
0.0424 \\
0.0275 \\
0.0210 \\
0.384 \\
0.269 \\
0.219 \\
0.133 \\
0.221\end{array}$ & $\begin{array}{l}0.482 \\
0.293 \\
0.699 \\
0.235 \\
0.694 \\
1.210 \\
0.267 \\
0.222 \\
0.135 \\
0.108 \\
0.122 \\
1.330 \\
0.809 \\
0.557 \\
0.357 \\
0.730\end{array}$ & $\begin{array}{l}0.27 \\
0.18 \\
0.32 \\
0.17 \\
0.24 \\
0.49 \\
0.15 \\
0.24 \\
0.19 \\
0.17 \\
0.12 \\
0.38 \\
0.27 \\
0.20 \\
0.21 \\
0.54\end{array}$ & $\begin{array}{r}0.85 \\
0.64 \\
0.93 \\
0.71 \\
0.99 \\
{ }^{b} 1.11 \\
0.99 \\
0.67 \\
0.61 \\
0.68 \\
0.72 \\
{ }^{b} 1.00 \\
1.05 \\
0.51 \\
0.58 \\
1.78\end{array}$ \\
\hline $\begin{array}{l}\text { Ellyin } \\
(1976) \\
\text { Ellyin } \\
(1977)\end{array}$ & $\begin{array}{l}\text { B2 } \\
\text { B4 } \\
\text { C2 } \\
\text { D2 } \\
\text { E2 } \\
\text { C3 } \\
\text { D3 } \\
\text { E3 }\end{array}$ & $\begin{array}{l}31 \\
22.9 \\
30 \\
29.7 \\
30 \\
30 \\
30 \\
30\end{array}$ & $\begin{array}{l}0.65 \\
0.65 \\
0.60 \\
0.79 \\
1.00 \\
0.60 \\
0.80 \\
1.00\end{array}$ & $\begin{array}{l}0.66 \\
0.39 \\
0.59 \\
0.77 \\
1.00 \\
0.61 \\
0.79 \\
1.00\end{array}$ & $\begin{array}{l}0.50 \\
0.84 \\
0.69 \\
0.52 \\
0.41 \\
0.56 \\
0.58 \\
0.45\end{array}$ & $\begin{array}{l}0.158 \\
0.328 \\
0.188 \\
0.127 \\
0.0861 \\
0.182 \\
0.122 \\
0.0861\end{array}$ & $\begin{array}{l}0.588 \\
1.348 \\
0.685 \\
0.562 \\
0.672 \\
0.663 \\
0.548 \\
0.672\end{array}$ & $\begin{array}{l}0.32 \\
0.39 \\
0.27 \\
0.24 \\
0.21 \\
0.32 \\
0.21 \\
0.19\end{array}$ & $\begin{array}{l}1.2 \\
\text { b } 1.2 \\
0.99 \\
1.1 \\
1.6 \\
1.2 \\
0.94 \\
1.5\end{array}$ \\
\hline $\begin{array}{l}\text { Schroeder } \\
(1984)\end{array}$ & $\begin{array}{l}\text { S1 } \\
\text { S2 } \\
\text { S3 }\end{array}$ & $\begin{array}{l}960 \\
960 \\
960\end{array}$ & $\begin{array}{l}0.00417 \\
0.0177 \\
0.0262\end{array}$ & $\begin{array}{l}1.00 \\
0.48 \\
1.00\end{array}$ & $\begin{array}{l}0.61 \\
0.18 \\
0.05\end{array}$ & $\begin{array}{l}0.132 \\
0.134 \\
0.0528\end{array}$ & $\begin{array}{l}0.360 \\
0.195 \\
0.0659\end{array}$ & $\begin{array}{l}0.22 \\
0.74 \\
1.06\end{array}$ & $\begin{array}{l}0.59 \\
1.07 \\
1.32\end{array}$ \\
\hline $\begin{array}{c}\text { Rodabaugh } \\
\text { (1980) }\end{array}$ & $\begin{array}{l}40-.3 \\
40-.5 \\
70-.2 \\
70-.4 \\
100-.2 \\
100-.4\end{array}$ & $\begin{array}{l}35 \\
37 \\
72 \\
72 \\
95 \\
95\end{array}$ & $\begin{array}{l}0.260 \\
0.458 \\
0.191 \\
0.441 \\
0.195 \\
0.362\end{array}$ & $\begin{array}{l}0.702 \\
0.644 \\
0.682 \\
1.000 \\
0.625 \\
0.979\end{array}$ & $\begin{array}{l}0.64 \\
0.50 \\
0.31 \\
0.17 \\
0.37 \\
0.13\end{array}$ & $\begin{array}{l}0.217 \\
0.172 \\
0.161 \\
0.0723 \\
0.145 \\
0.0678\end{array}$ & $\begin{array}{l}0.618 \\
0.540 \\
0.349 \\
0.180 \\
0.286 \\
0.147\end{array}$ & $\begin{array}{l}0.34 \\
0.34 \\
0.52 \\
0.43 \\
0.39 \\
0.52\end{array}$ & $\begin{array}{l}0.97 \\
1.08 \\
1.13 \\
1.06 \\
0.77 \\
1.13\end{array}$ \\
\hline
\end{tabular}

aSee Nomenclature and Sect. 2 for definitions.

${ }^{b}$ Ratio based on assumption that $M_{u o}{ }^{*}=1.000$. See Text. 
Table 2. Limit-load comparisons for in-plane moment loads on the branch

\begin{tabular}{|c|c|c|c|c|c|c|c|c|c|}
\hline \multirow{2}{*}{$\begin{array}{l}\text { Data source } \\
\text { reference }\end{array}$} & \multirow{2}{*}{$\begin{array}{l}\text { Model } \\
\text { Number }\end{array}$} & \multicolumn{3}{|c|}{ Dimensional parameters } & \multicolumn{3}{|c|}{ Normalized limit load } & \multicolumn{2}{|c|}{ Limit-load ratio } \\
\hline & & $\mathrm{D} / \mathrm{T}$ & d/D & $\mathbf{t} \mathbf{T}$ & $\mathbf{M}_{\mathbf{2}}^{*}$ & $\mathbf{M}_{\varepsilon}^{*}$ & $\mathbf{M}_{\mathbf{i}} *$ & MyM & $\mathbf{M}_{\mathbf{q}} / \mathbf{M}_{\mathbf{l}}$ \\
\hline $\begin{array}{l}\text { Schroeder } \\
(1974)\end{array}$ & $\begin{array}{l}\text { T8 } \\
\text { T5 } \\
\text { T14 } \\
\text { T11 } \\
\text { T12 }\end{array}$ & $\begin{array}{l}24 \\
25 \\
25 \\
25 \\
27\end{array}$ & $\begin{array}{l}0.52 \\
0.75 \\
1.00 \\
0.75 \\
1.00\end{array}$ & $\begin{array}{l}0.52 \\
0.75 \\
1.00 \\
0.75 \\
1.00\end{array}$ & $\begin{array}{l}0.91 \\
0.84 \\
0.64 \\
0.47 \\
0.49\end{array}$ & $\begin{array}{l}0.266 \\
0.150 \\
0.0972 \\
0.150 \\
0.0924\end{array}$ & $\begin{array}{r}{ }^{b} 1.693 \\
{ }^{b} 1.150 \\
0.863 \\
{ }^{b} 1.150 \\
0.830\end{array}$ & $\begin{array}{l}0.29 \\
0.18 \\
0.15 \\
0.32 \\
0.19\end{array}$ & $\begin{array}{r}{ }^{b} 1.1 \\
b 1.2 \\
1.3 \\
b 2.1 \\
1.7\end{array}$ \\
\hline $\begin{array}{c}\text { Schroeder } \\
\text { (1978) }\end{array}$ & $\begin{array}{l}\text { T15 } \\
\text { T19 }\end{array}$ & $\begin{array}{l}56.5 \\
34.5\end{array}$ & $\begin{array}{l}1.00 \\
0.40\end{array}$ & $\begin{array}{l}1.00 \\
0.80\end{array}$ & $\begin{array}{l}0.50 \\
0.70\end{array}$ & $\begin{array}{l}0.0564 \\
0.155\end{array}$ & $\begin{array}{l}0.574 \\
0.918\end{array}$ & $\begin{array}{l}0.11 \\
0.22\end{array}$ & $\begin{array}{l}1.1 \\
1.3\end{array}$ \\
\hline $\begin{array}{l}\text { Ellyin } \\
\text { (1976) }\end{array}$ & B1 & 31.0 & 0.65 & 0.66 & 0.66 & 0.161 & ${ }^{b} 1.174$ & 0.24 & ${ }^{\mathrm{b}} 1.5$ \\
\hline $\begin{array}{l}\text { Ellyin } \\
\text { (1977) }\end{array}$ & $\begin{array}{l}\text { D1 } \\
\text { E1 }\end{array}$ & $\begin{array}{l}30.1 \\
30.0\end{array}$ & $\begin{array}{l}0.79 \\
1.00\end{array}$ & $\begin{array}{l}0.79 \\
1.00\end{array}$ & $\begin{array}{l}0.63 \\
0.46\end{array}$ & $\begin{array}{l}0.122 \\
0.0861\end{array}$ & $\begin{array}{l}0.995 \\
0.788\end{array}$ & $\begin{array}{l}0.19 \\
0.19\end{array}$ & $\begin{array}{l}1.6 \\
1.7\end{array}$ \\
\hline $\begin{array}{l}\text { Rodabaugh } \\
(1980)\end{array}$ & $\begin{array}{l}1 \\
2 \\
3 \\
4 \\
5 \\
6 \\
7 \\
8 \\
9 \\
10 \\
11 \\
12 \\
13 \\
14 \\
15 \\
16 \\
17 \\
18 \\
19\end{array}$ & $\begin{array}{l}28.98 \\
29.85 \\
29.85 \\
34.78 \\
24.62 \\
41.46 \\
39.84 \\
26.08 \\
21.91 \\
17.81 \\
36.52 \\
24.90 \\
17.81 \\
40.89 \\
29.85 \\
29.85 \\
37.14 \\
25.48 \\
17.53\end{array}$ & $\begin{array}{l}0.339 \\
0.362 \\
0.362 \\
0.327 \\
0.327 \\
0.340 \\
0.464 \\
0.464 \\
0.464 \\
0.464 \\
0.638 \\
0.638 \\
0.638 \\
0.649 \\
0.649 \\
0.649 \\
0.812 \\
0.812 \\
0.812\end{array}$ & $\begin{array}{l}0.485 \\
0.630 \\
0.800 \\
2.937 \\
2.079 \\
2.222 \\
2.909 \\
1.905 \\
1.600 \\
1.301 \\
2.917 \\
1.989 \\
1.423 \\
0.973 \\
0.710 \\
0.710 \\
2.712 \\
1.860 \\
1.280\end{array}$ & $\begin{array}{c}{ }^{c} 1.00 \\
{ }^{c} 1.00 \\
{ }^{c} 1.00 \\
028 \\
0.44 \\
0.30 \\
0.23 \\
0.43 \\
0.58 \\
0.81 \\
0.24 \\
0.41 \\
0.66 \\
0.68 \\
1.00 \\
1.09 \\
0.26 \\
0.46 \\
0.81\end{array}$ & $\begin{array}{l}0.312 \\
0.228 \\
0.179 \\
0.0464 \\
0.0826 \\
0.0536 \\
0.0360 \\
0.072 ? \\
0.0974 \\
0.138 \\
0.0324 \\
0.0614 \\
0.107 \\
0.0893 \\
0.151 \\
0.151 \\
0.0306 \\
0.0573 \\
0.107\end{array}$ & $\begin{array}{r}{ }^{b} 1.652 \\
{ }^{b} 1.253 \\
0.987 \\
0.249 \\
0.418 \\
0.301 \\
0.235 \\
0.443 \\
0.576 \\
0.786 \\
0.245 \\
0.435 \\
0.718 \\
0.693 \\
b^{b} 1.112 \\
b_{1} 1.112 \\
0.261 \\
0.459 \\
0.805\end{array}$ & $\begin{array}{l}0.31 \\
0.23 \\
0.18 \\
0.17 \\
0.19 \\
0.18 \\
0.16 \\
0.17 \\
0.17 \\
0.17 \\
0.14 \\
0.15 \\
0.16 \\
0.13 \\
0.15 \\
0.14 \\
0.12 \\
0.12 \\
0.13\end{array}$ & $\begin{array}{c}{ }^{b} 1.0 \\
{ }^{b} 1.0 \\
0.99 \\
0.89 \\
0.95 \\
1.0 \\
1.0 \\
1.0 \\
0.99 \\
0.97 \\
1.0 \\
1.1 \\
1.1 \\
1.0 \\
{ }^{b} 1.0 \\
b 0.92 \\
1.0 \\
1.0 \\
0.99\end{array}$ \\
\hline $\begin{array}{l}\text { Rodabaugh } \\
\text { (1980) }\end{array}$ & $\begin{array}{l}8 C 1-90 \\
8 C 2-90 \\
4 C 1-90 \\
8 T 1-90 \\
8 T 2-90\end{array}$ & $\begin{array}{l}31.04 \\
26.78 \\
19.52 \\
31.04 \\
28.83\end{array}$ & $\begin{array}{l}1.000 \\
1.000 \\
1.000 \\
1.000 \\
1.000\end{array}$ & $\begin{array}{l}1.000 \\
1.000 \\
1.000 \\
1.000 \\
1.000\end{array}$ & $\begin{array}{l}0.75 \\
0.88 \\
0.89 \\
0.90 \\
0.99\end{array}$ & $\begin{array}{l}0.0842 \\
0.0929 \\
0.115 \\
0.0842 \\
0.0884\end{array}$ & $\begin{array}{l}0.774 \\
0.834 \\
0.976 \\
0.774 \\
0.803\end{array}$ & $\begin{array}{l}0.11 \\
0.11 \\
0.13 \\
0.094 \\
0.089\end{array}$ & $\begin{array}{l}1.0 \\
0.95 \\
1.1 \\
0.86 \\
0.81\end{array}$ \\
\hline $\begin{array}{l}\text { Rodabaugh } \\
\text { (1980) }\end{array}$ & $\begin{array}{l}40-3 \\
40-.5 \\
70-.2 \\
70-.4 \\
100-.2 \\
100-.4\end{array}$ & $\begin{array}{l}35 \\
37 \\
72 \\
72 \\
95 \\
95\end{array}$ & $\begin{array}{l}0.260 \\
0.458 \\
0.191 \\
0.441 \\
0.195 \\
0.362\end{array}$ & $\begin{array}{l}0.702 \\
0.644 \\
1.000 \\
1.000 \\
0.625 \\
0.979\end{array}$ & $\begin{array}{l}0.74 \\
0.79 \\
0.47 \\
0.39 \\
0.64 \\
0.35\end{array}$ & $\begin{array}{l}0.217 \\
0.172 \\
0.110 \\
0.0723 \\
0.145 \\
0.0678\end{array}$ & $\begin{array}{l}{ }^{b} 1.039 \\
{ }^{b} 1.101 \\
0.508 \\
0.508 \\
0.708 \\
0.452\end{array}$ & $\begin{array}{l}0.29 \\
0.22 \\
0.23 \\
0.19 \\
0.23 \\
0.19\end{array}$ & $\begin{array}{l}1.3 \\
1.3 \\
1.1 \\
1.3 \\
1.1 \\
1.3\end{array}$ \\
\hline
\end{tabular}

${ }^{2}$ See Nomenclature for definitions.

${ }^{b}$ Ratio based on assumption that $M_{u i}{ }^{*}=1.000$. See text.

The branch pipe/yield in these tests. 
Table 3. Summary of limit-load ratios for moment loads on the branch

\begin{tabular}{|c|c|c|c|c|c|c|}
\hline Group & Ratio & Maximum & Minimum & Average & $\begin{array}{c}\text { Std. Dev. } \\
\text { o }\end{array}$ & $\frac{\sigma}{A v g}$ \\
\hline $\begin{array}{c}\text { Table } 1 \text { (out-of-plane) } \\
\text { All tests }\end{array}$ & $\begin{array}{l}\mathbf{M}_{d} \mathbf{M}_{t} \\
\mathbf{M}_{u d} / \mathbf{M}_{t}\end{array}$ & $\begin{array}{l}1.06 \\
1.78\end{array}$ & $\begin{array}{l}0.120 \\
0.590\end{array}$ & $\begin{array}{l}0.313 \\
0.997\end{array}$ & $\begin{array}{l}0.1850 \\
0.3000\end{array}$ & $\begin{array}{l}0.589 \\
0.301\end{array}$ \\
\hline Branch connections & $\begin{array}{l}\mathbf{M}_{d} \mathbf{M}_{t} \\
\mathbf{M}_{w o} / M_{t}\end{array}$ & $\begin{array}{l}1.06 \\
1.78\end{array}$ & $\begin{array}{l}0.120 \\
0.590\end{array}$ & $\begin{array}{l}0.293 \\
0.992\end{array}$ & $\begin{array}{l}0.1920 \\
0.3330\end{array}$ & $\begin{array}{l}0.655 \\
0.326\end{array}$ \\
\hline Tubular joints & $\begin{array}{l}\mathbf{M}_{d} \mathbf{M}_{t} \\
\mathbf{M}_{\mathrm{ud}} d \mathbf{M}_{t}\end{array}$ & $\begin{array}{l}0.52 \\
1.13\end{array}$ & $\begin{array}{l}0.340 \\
0.770\end{array}$ & $\begin{array}{l}0.423 \\
1.023\end{array}$ & $\begin{array}{l}0.0821 \\
0.1370\end{array}$ & $\begin{array}{l}0.194 \\
0.134\end{array}$ \\
\hline $\begin{array}{c}\text { Table } 2 \text { (in-plane) } \\
\text { All tests }\end{array}$ & $\begin{array}{l}\mathbf{M}_{\mathrm{d}} \mathbf{M}_{\mathrm{t}} \\
\mathbf{M}_{\mathrm{u} i} / \mathbf{M}_{\mathrm{t}}\end{array}$ & $\begin{array}{l}0.32 \\
2.10\end{array}$ & $\begin{array}{l}0.089 \\
0.810\end{array}$ & $\begin{array}{l}0.178 \\
1.140\end{array}$ & $\begin{array}{l}0.0574 \\
0.2650\end{array}$ & $\begin{array}{l}0.322 \\
0.232\end{array}$ \\
\hline Branch connections & $\begin{array}{l}M_{d} M_{t} \\
M_{u i r} / M_{t}\end{array}$ & $\begin{array}{l}0.32 \\
2.10\end{array}$ & $\begin{array}{l}0.110 \\
1.100\end{array}$ & $\begin{array}{l}0.208 \\
1.460\end{array}$ & $\begin{array}{l}0.0625 \\
0.3200\end{array}$ & $\begin{array}{l}0.300 \\
0.219\end{array}$ \\
\hline Tubular joints & $\begin{array}{l}M_{d} / M_{t} \\
M_{u i r} / M_{t}\end{array}$ & $\begin{array}{l}0.31 \\
1.30\end{array}$ & $\begin{array}{l}0.089 \\
0.810\end{array}$ & $\begin{array}{l}0.168 \\
1.034\end{array}$ & $\begin{array}{l}0.0530 \\
0.1250\end{array}$ & $\begin{array}{l}0.315 \\
0.121\end{array}$ \\
\hline
\end{tabular}


Table 4. Udoguchi's limit moment tests

\begin{tabular}{|c|c|c|c|c|c|}
\hline $\begin{array}{l}\text { Test } \\
\text { No. }\end{array}$ & Identification" & $\begin{array}{c}\mathrm{M}_{\mathrm{b}}^{\mathrm{b}} \\
10^{6} \mathrm{~kg}-\mathrm{mm}\end{array}$ & $\mathbf{M}_{\mathbf{t}}^{* c}$ & $\mathbf{M}_{\mathbf{2}}^{* d}$ & $M_{\infty} *$ \\
\hline 22 & CF1M & 3.7 & 0.83 & 0.127 & 0.567 \\
\hline 23 & CF2M & 2.0 & 1.57 & 0.205 & 0.726 \\
\hline 24 & CW1M & 2.2 & 0.50 & 0.127 & 0.567 \\
\hline 25 & $\mathrm{CW} 2 \mathrm{M}$ & 1.6 & 1.26 & 0.205 & 0.726 \\
\hline 26 & CF1T & 4.6 & 1.04 & 0.127 & \\
\hline 27 & CF2T & 1.15 & 0.90 & 0.205 & \\
\hline 28 & CW1T & 4.3 & 0.97 & 0.127 & \\
\hline 29 & CW2T & 1.15 & 0.90 & 0.205 & \\
\hline 30 & SF1M & 1.8 & 0.48 & 0.127 & 0.567 \\
\hline 31 & SF1T & 2.0 & 0.54 & 0.127 & \\
\hline 32 & SFIMT & $1.8^{*}$ & 0.48 & 0.127 & \\
\hline 33 & SW1M & 2.2 & 0.59 & 0.127 & 0.567 \\
\hline 34 & SW1T & 1.6 & 0.43 & 0.127 & \\
\hline 35 & SW1MT & $1.8^{*}$ & 0.48 & 0.127 & \\
\hline 36 & SF2M & 0.75 & 0.70 & 0.205 & 0.726 \\
\hline 37 & SF2T & 0.75 & 0.70 & 0.205 & \\
\hline 38 & SF2MT & $0.90^{*}$ & 0.84 & 0.205 & \\
\hline 39 & SW2M & 0.70 & 0.65 & 0.205 & 0.726 \\
\hline 40 & SW2T & 0.75 & 0.70 & 0.205 & \\
\hline 41 & SW2MT & $0.62^{*}$ & 0.58 & 0.205 & \\
\hline
\end{tabular}

${ }^{a}$ Identification symbols are defined as follows:

$\mathrm{C}=$ carbon steel, $\mathbf{S}=$ stainless steel

$\mathrm{F}=$ forged, $\mathbf{W}=$ welded

$1: \mathrm{D} / \mathrm{T}=25.4, \mathrm{~d} / \mathrm{D}=0.76, \mathrm{t} / \mathrm{T}=0.87, \mathrm{~d}=158.1 \mathrm{~mm}$

$\mathrm{t}=7.1 \mathrm{~mm}$

$2: \mathrm{D} / \mathrm{T}=25.4, \mathrm{~d} / \mathrm{D}=0.45, \mathrm{t} / \mathrm{T}=0.70, \mathrm{~d}=94.16 \mathrm{~mm}$

$\mathrm{t}=5.74 \mathrm{~mm}$

$M=$ out-of-plane moment load, $T=$ torsional moment test

$\mathrm{MT}=$ combined out-of-plane and torsional test

${ }^{b} M_{t}=$ limit moment determined from load displacement plots in accordance with 11-1430 of the Code. An asterisk (") in this column indicates limit moment from $M_{0}$ vs $\delta$ plots, see Fig. 2 and Table 6.

${ }^{c} M_{\mathrm{t}}{ }^{*}=\mathrm{M}_{\mathrm{t}} /\left(\mathrm{d}^{2} \mathrm{i}_{\mathrm{y}}\right)$

$\mathrm{S}_{\mathrm{y}}=245 \mathrm{MPa}$ for $\mathrm{CXXX}$ specimens

$\mathrm{S}_{\mathrm{y}}=206 \mathrm{MPa}$ for SXXX specimens

Apparently these are code specified minimum yield strengths.

${ }^{d} M_{c} *=(x / 4) / B_{2 b}$, where $B_{2 b}$ is defined by Eq. 5 of text.

esee Eq. 8 of text. 
Table 5. Limit moment ratios from corresponding pairs of test specimens from Udoguchi's Tests

\begin{tabular}{|c|c|c|c|c|c|c|c|c|}
\hline \multicolumn{3}{|c|}{ Moment direction } & \multicolumn{3}{|c|}{ Construction } & \multicolumn{3}{|c|}{ Materials } \\
\hline $\mathbf{M}_{\mathbf{0}}$ & Torsion & $\begin{array}{l}\text { MorT } \\
\text { Ratio }\end{array}$ & Forged & Welded & $\begin{array}{l}\text { F/W } \\
\text { Ratio }\end{array}$ & Carbon & Stainless & $\underset{\text { Ratio }}{\text { CSS }}$ \\
\hline 3.7 & 4.6 & 0.80 & 3.7 & 2.2 & 1.68 & 3.7 & 1.8 & 2.06 \\
\hline 2.0 & 1.15 & 1.74 & 2.0 & 1.6 & 1.25 & 2.0 & 0.75 & 2.67 \\
\hline 2.2 & 4.3 & 0.51 & 4.6 & 4.3 & 1.07 & 2.2 & 2.2 & 1.00 \\
\hline 1.6 & 1.15 & 1.39 & 1.15 & 1.15 & 1.00 & 1.6 & 0.70 & 2.29 \\
\hline 1.8 & 2.0 & 0.90 & 1.8 & 2.2 & 0.82 & 4.6 & 2.0 & 2.30 \\
\hline 2.2 & 1.6 & 1.38 & 2.0 & 1.6 & 1.25 & 1.15 & 0.75 & 1.53 \\
\hline 0.75 & 0.75 & 1.00 & 1.8 & 1.8 & 1.00 & 4.3 & 1.6 & 2.69 \\
\hline \multirow[t]{3}{*}{0.70} & 0.75 & 0.93 & 0.75 & 0.70 & 1.07 & 1.15 & 0.75 & 1.53 \\
\hline & & & 0.75 & 0.75 & 1.00 & & & \\
\hline & & & 0.90 & 0.62 & 1.45 & & & \\
\hline \multicolumn{2}{|c|}{ Average } & 1.08 & & & 1.16 & & & 2.01 \\
\hline
\end{tabular}

abstracted from Table 4. 
Table 6. Limit loads for combined out-of-plane and torsional moments"

\begin{tabular}{|c|c|c|c|c|c|c|}
\hline \multirow{2}{*}{$\begin{array}{l}\text { Test } \\
\text { No. }\end{array}$} & \multicolumn{2}{|c|}{ MT tests } & \multirow{2}{*}{$\begin{array}{c}\text { M-only } \\
\text { M }\end{array}$} & \multirow{2}{*}{$\begin{array}{c}\text { T-only } \\
T\end{array}$} & \multirow[t]{2}{*}{$\mathbf{M}_{\mathbf{M} I} / \mathbf{M}$} & \multirow[t]{2}{*}{$\mathrm{T}_{\mathrm{M}} \boldsymbol{T}$} \\
\hline & $\mathbf{M}_{\mathbf{M T}}$ & $\mathbf{T}_{\mathbf{M T}}$ & & & & \\
\hline $\begin{array}{l}32 \\
35 \\
38 \\
41\end{array}$ & $\begin{array}{l}1.8 \\
1.8 \\
0.90 \\
0.62\end{array}$ & $\begin{array}{l}1.4 \\
0.82 \\
0.27 \\
0.37\end{array}$ & $\begin{array}{l}1.8 \\
2.2 \\
0.75 \\
0.70\end{array}$ & $\begin{array}{l}2.0 \\
1.6 \\
0.75 \\
0.75\end{array}$ & $\begin{array}{l}1.00 \\
0.82 \\
1.20 \\
0.89\end{array}$ & $\begin{array}{l}0.70 \\
0.51 \\
0.36 \\
0.49\end{array}$ \\
\hline & & & & Avera & 0.98 & 0.52 \\
\hline
\end{tabular}

${ }^{\mathrm{a}}$ Abstracted from Table 4. 
Table 7. Comparisons between WRC-297 stresses set equal to $S$, and limit load tests

\begin{tabular}{|c|c|c|c|c|c|c|c|}
\hline \multirow[b]{3}{*}{ Model } & \multirow[b]{3}{*}{$\mathbf{D} / \mathbf{T}$} & \multirow[b]{3}{*}{$d / D$} & \multirow[b]{3}{*}{$\mathbf{t} / \mathbf{T}$} & \multirow[b]{3}{*}{$\frac{M_{1}^{*}}{d^{2} S^{2}}$} & \multicolumn{3}{|c|}{$M^{\prime} /\left(d^{2} t S_{j}\right)^{b}$} \\
\hline & & & & & \multicolumn{2}{|c|}{ Run pipe } & \multirow{2}{*}{$\begin{array}{c}\text { Branch } \\
\text { total }^{e}\end{array}$} \\
\hline & & & & & Membrane $^{c}$ & Total $^{d}$ & \\
\hline $\mathrm{T} 4$ & 25 & 0.5 & 0.5 & 0.72 & 1.00 & 0.133 & 0.052 \\
\hline T18 & 34.5 & 0.4 & 0.8 & 0.57 & 0.91 & 0.057 & 0.046 \\
\hline $\mathrm{T} 21$ & 34.5 & 0.3 & 0.6 & 0.75 & 1.24 & 0.099 & 0.048 \\
\hline $\mathrm{T} 24$ & 34.7 & 0.2 & 0.4 & 0.90 & 2.57 & 0.27 & 0.068 \\
\hline T29 & 45 & 0.4 & 1.33 & 0.33 & 0.35 & 0.026 & 0.060 \\
\hline T33 & 25 & 0.4 & 0.4 & 1.0 & 1.25 & 0.236 & 0.056 \\
\hline T30 & 45 & 0.2 & 0.67 & 1.1 & 1.03 & 0.114 & 0.068 \\
\hline T31 & 45 & 0.3 & 0.9 & 0.62 & 0.55 & 0.056 & 0.070 \\
\hline T32 & 34.5 & 0.5 & 0.5 & 0.41 & 0.58 & 0.116 & 0.046 \\
\hline S1 & 960 & 0.00417 & 1.00 & 0.61 & 1.78 & 0.129 & 0.147 \\
\hline S2 & 960 & 0.0177 & 0.48 & 0.18 & 0.94 & 0.081 & 0.028 \\
\hline S3 & 960 & 0.0262 & 1.00 & 0.05 & 0.42 & 0.022 & 0.026 \\
\hline
\end{tabular}

${ }^{a} M_{t}=$ test limit moment defined by the intersection of a tangent to the plastic response of the experimenta! load-displacement curve with the extrapolated elastic response line.

${ }^{b} M^{\prime}=$ moment load corresponding to a calculated elastic stress of $S_{\mathbf{y}}$.

'See Eq. 16 of text.

${ }^{d}$ See Eq. 17 of text.

'See Eq. 19 of text. 
Table 8. Ratios from Table 7 and

Code ratios from Table 1

\begin{tabular}{|c|c|c|c|c|}
\hline \multirow{2}{*}{ Model } & \multicolumn{4}{|c|}{$\mathbf{M}^{\prime} / \mathbf{M}_{\mathbf{L}}$} \\
\hline & Membrane" & Total $^{\mathbf{a}}$ & Branch" & Code \\
\hline T4 & 1.39 & 0.185 & 0.072 & 0.38 \\
\hline $\mathrm{T} 18$ & 1.60 & 0.100 & 0.081 & 0.27 \\
\hline $\mathrm{T} 21$ & 1.65 & 0.132 & 0.064 & 0.32 \\
\hline $\mathrm{T} 24$ & 2.86 & 0.300 & 0.076 & 0.49 \\
\hline T29 & 1.06 & 0.079 & 0.182 & 0.24 \\
\hline T33 & 1.25 & 0.236 & 0.056 & 0.38 \\
\hline T30 & 0.94 & 0.104 & 0.062 & 0.20 \\
\hline T31 & 0.89 & 0.090 & 0.113 & 0.21 \\
\hline T32 & 1.42 & 0.283 & 0.112 & 0.54 \\
\hline Avg. & 1.45 & 0.168 & 0.0908 & 0.337 \\
\hline St. Dev./Avg. & 0.409 & 0.515 & 0.438 & 0.360 \\
\hline S1 & 2.92 & 0.211 & 0.241 & 0.22 \\
\hline S2 & 5.12 & 0.450 & 0.156 & 0.74 \\
\hline S3 & 8.40 & 0.440 & 0.520 & 1.06 \\
\hline Avg. & 2.46 & 0.218 & 0.145 & 0.420 \\
\hline St. Dev./Avg. & 0.907 & 0.597 & 0.907 & 0.613 \\
\hline
\end{tabular}

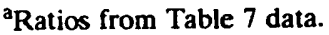

${ }^{\text {b } R a t i o s ~ f r o m ~ T a b l e ~} 1$. 
Table 9. Comparison of limit moments for run pipe

\begin{tabular}{|c|c|c|c|c|c|}
\hline \multirow{3}{*}{$\mathbf{R} \mathbf{T}$} & \multicolumn{5}{|c|}{$\mathrm{M} /\left(\mathrm{D}^{2} \mathrm{TS} \mathrm{S}_{\mathrm{\gamma}}\right)$} \\
\hline & \multicolumn{3}{|c|}{ Code" } & \multicolumn{2}{|c|}{ Cracked pipe model ${ }^{b}$} \\
\hline & $U T=r / R$ & $t / T=4 r / R$ & $t_{p} / T=10 \mathrm{r} / \mathrm{R}$ & $\mathbf{r} / \mathbf{R}=\mathbf{0 . 0 5}$ & $\mathbf{r} / \mathbf{R}=0.5$ \\
\hline 5 & 0.609 & 0.785 & 0.785 & 0.975 & 0.716 \\
\hline 10 & 0.512 & 0.724 & 0.785 & 0.975 & 0.716 \\
\hline 20 & 0.431 & 0.609 & 0.765 & 0.975 & 0.716 \\
\hline 30 & 0.389 & 0.550 & 0.692 & 0.975 & 0.716 \\
\hline 40 & 0.362 & 0.512 & 0.644 & 0.975 & 0.716 \\
\hline 50 & 0.342 & 0.484 & 0.609 & 0.975 & 0.716 \\
\hline
\end{tabular}

${ }^{\mathrm{a}} \mathrm{M} /\left(\mathrm{D}^{3} \mathrm{TS}_{\mathrm{y}}\right)=(\pi / 4) / \mathrm{B}_{2 r}$ where $\mathrm{B}_{2 r}$ is defined by Eq. 20 of text.

${ }^{\text {bSee Eq. }} 21$ of text. 
Table 10. Internal pressure effect from corresponding pairs tested with and without internal pressure

\begin{tabular}{|c|c|c|c|c|c|c|}
\hline \multirow[b]{2}{*}{$\begin{array}{l}\text { Bending } \\
\text { plane }\end{array}$} & \multirow{2}{*}{ Pair } & \multicolumn{2}{|c|}{$M_{N} /\left(d^{2} t S_{j}\right)$} & \multirow{2}{*}{ Ratio } & \multirow[b]{2}{*}{$\begin{array}{c}\mathrm{PD} / 2 \mathrm{TS}, \\
\text { for } \mathrm{P}>\mathrm{O}\end{array}$} & \multirow[b]{2}{*}{$\begin{array}{l}\text { Code } \\
\text { ratiob }\end{array}$} \\
\hline & & $\mathbf{P}=\mathbf{O}$ & $P>0$ & & & \\
\hline Out & T10-T13 & 0.48 & 0.32 & 0.67 & 0.56 & 0.72 \\
\hline Out & C2-C3 & 0.69 & 0.56 & 0.81 & 0.28 & 0.86 \\
\hline Out & D2-D3 & 0.52 & 0.58 & 1.12 & 0.32 & 0.84 \\
\hline Out & E2-E3 & 0.41 & 0.45 & 1.10 & 0.32 & 0.84 \\
\hline In & T5-T11 & 0.84 & 0.47 & 0.56 & 0.33 & 0.83 \\
\hline In & T14-T12 & 0.64 & 0.49 & 0.77 & 0.27 & 0.87 \\
\hline & Average & & & 0.84 & & 0.83 \\
\hline
\end{tabular}

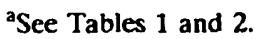

${ }^{\mathrm{b}}$ Code ratio $=\left(1-0.5 \mathrm{PD}_{\delta} / \mathrm{TS}_{\mathrm{y}}\right)$. 
Table 11. Comparison of interaction effects by

Code Class 1 piping rules and by separate

ends evaluation rules

\begin{tabular}{|c|c|c|c|}
\hline \multirow[b]{2}{*}{$\begin{array}{l}\text { Pipe } \\
\text { sizes }\end{array}$} & \multirow{2}{*}{$Z_{\sqrt{2}} \mathbf{Z}^{b}$} & \multicolumn{2}{|c|}{$\mathbf{M}_{0} / \mathbf{M}_{e l}{ }^{c}$} \\
\hline & & Fig $40^{2}$ & Fig $4 e^{6}$ \\
\hline $1 \times 24$ & 0.000466 & 1.000 & 1.004 \\
\hline $4 \times 24$ & 0.0113 & 1.006 & 1.102 \\
\hline $8 \times 24$ & 0.0590 & 1.030 & 1.531 \\
\hline$f$ & 0.100 & 1.050 & 1.900 \\
\hline $14 \times 24$ & 0.215 & 1.108 & 1.365 \\
\hline $20 \times 24$ & 0.598 & 1.299 & 1.067 \\
\hline$f$ & 0.667 & 1.333 & 1.050 \\
\hline $24 \times 24$ & 1.000 & 1.000 & 1.000 \\
\hline
\end{tabular}

${ }^{a}$ Schedule $\mathbf{4 0}$ branch and run pipe.

${ }^{b} \mathrm{Z}_{\mathrm{b}}=$ branch pipe section modulus.

$\mathrm{Z}_{\mathrm{T}}=$ run pipe section modulus.

${ }^{c} M_{c 2}=M$ by separate ends evaluation.

$M_{c 1}=M$ by Class 1 rules.

Based on $B_{2 b}=B_{2 r} ;$ See Eq. 23 of text.

${ }^{d}$ Class 1 rules: $M_{b}=M, M_{r}=0.5 M$.

${ }^{e}$ Class 1 rules: $M_{b}=M, M_{r}=9 M$.

f Worst case $\mathbf{Z}_{\mathbf{b}} / \mathbf{Z}_{\mathbf{T}}$ 
Table 12 Comparison of interaction effects by

Class 1 piping rules with AWS (1982) Rules, Fig. 4 moment ratios

\begin{tabular}{c|c|c}
\hline \multirow{2}{*}{$\begin{array}{c}\text { Size } \\
\text { (Sched 40) }\end{array}$} & \multicolumn{2}{|c}{ M/M $^{\circ}$} \\
\cline { 2 - 3 } Code & AWS $^{\mathbf{b}}$ \\
\hline $1 \times 24$ & 0.995 & 1.000 \\
$4 \times 24$ & 0.906 & 1.000 \\
$8 \times 24$ & 0.761 & 1.000 \\
$14 \times 24$ & 0.593 & 0.853 \\
$20 \times 24$ & 0.455 & 0.598 \\
$24 \times 24$ & 0.386 & 0.370 \\
\hline
\end{tabular}

${ }^{2}$ See Eq. 28.

'See Eq. 29. 


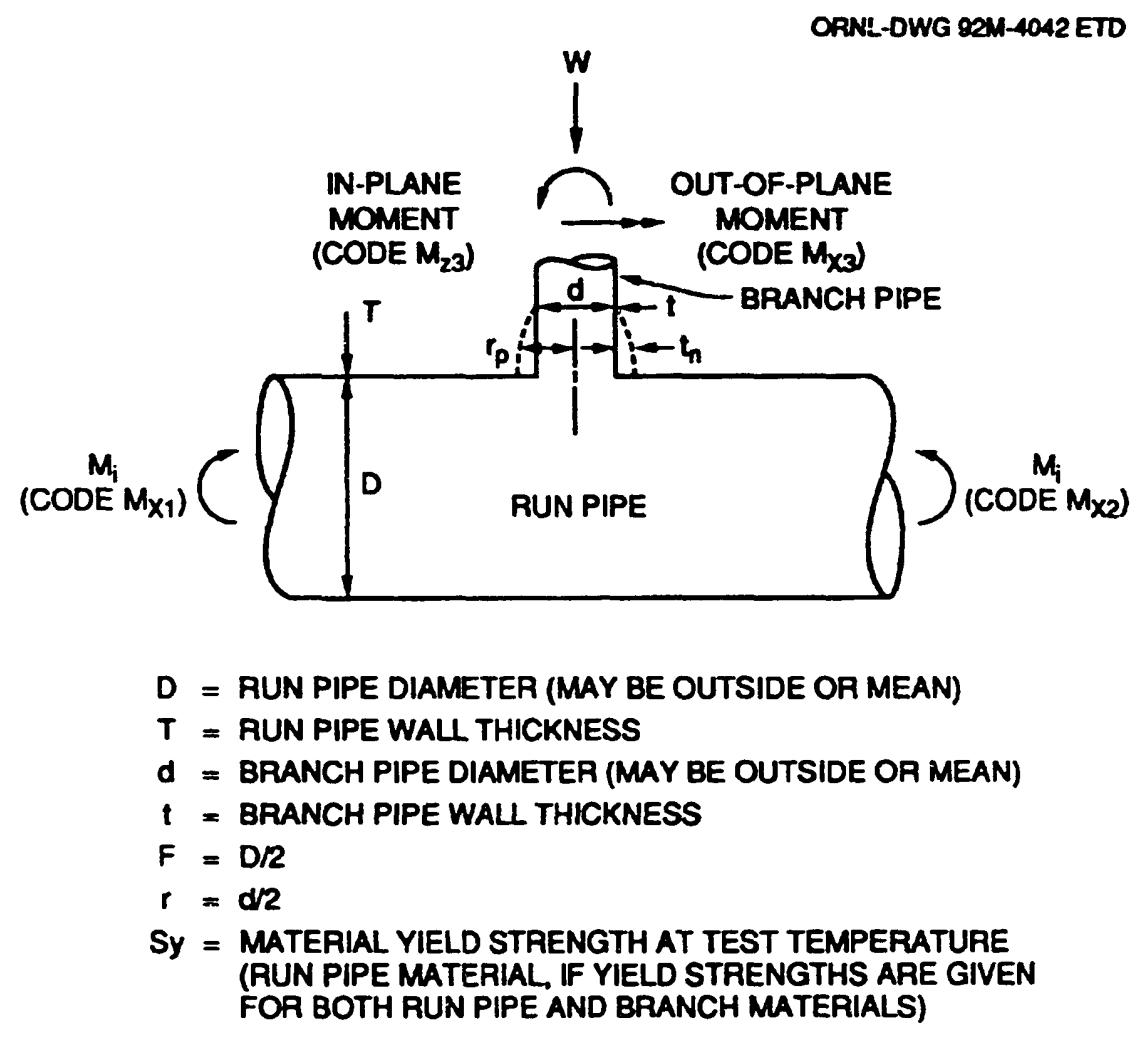

Figure 1. Nomenclature 


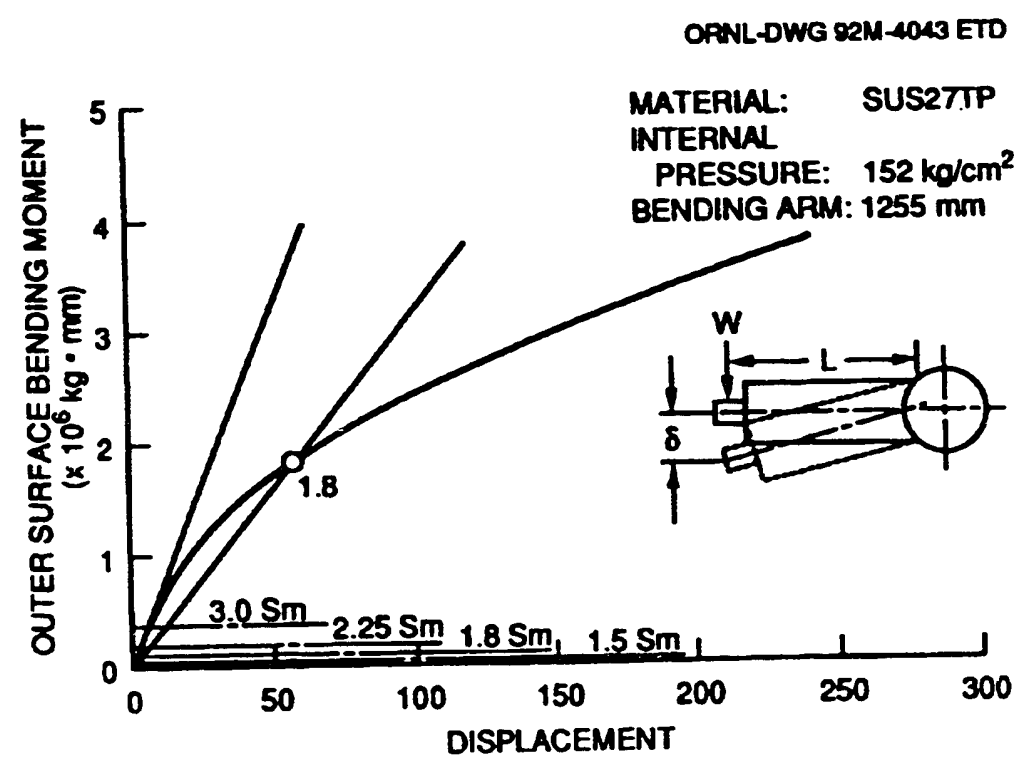

(a)

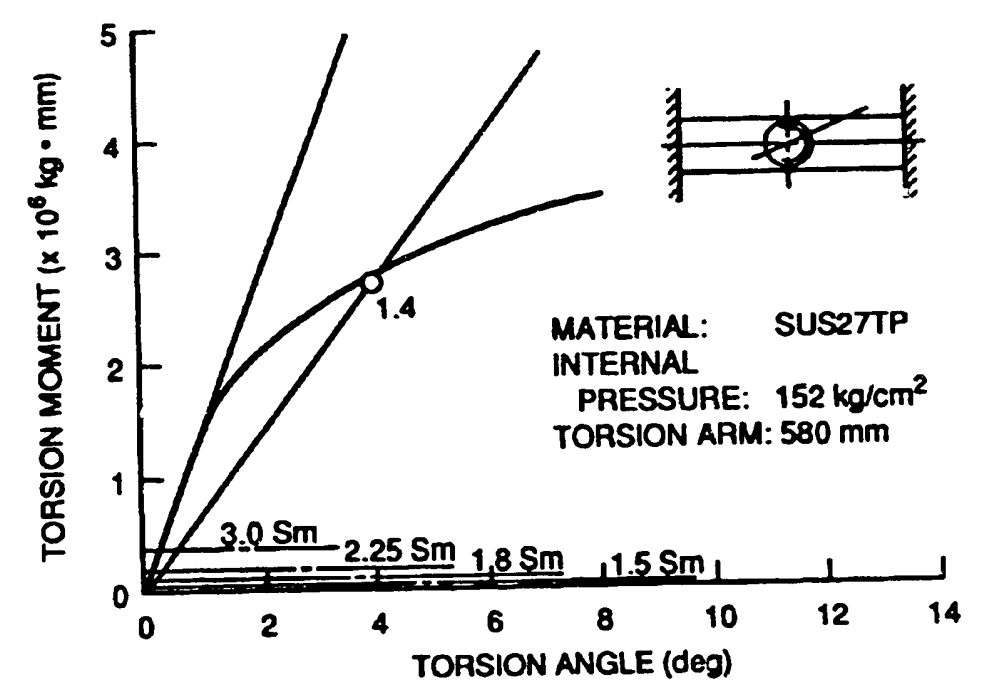

(b)

Figure 2. From Udoguchi (1973), Combined Bending and Torsion Test 


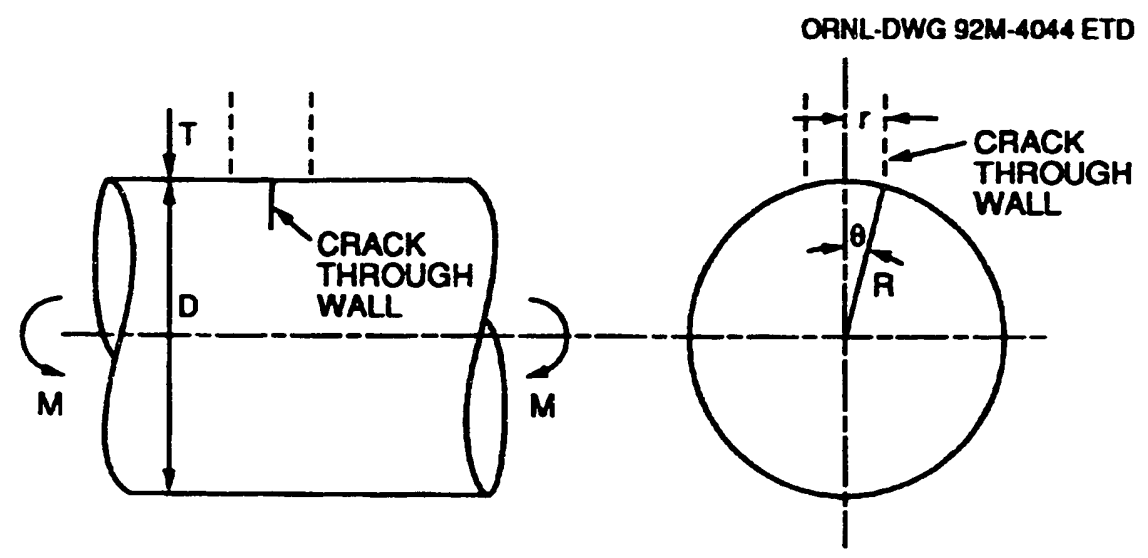

Figure 3. Cracked Pipe Model for Run Pipe Bending Moment 
ORNL-DWG D2M-4045 ETD

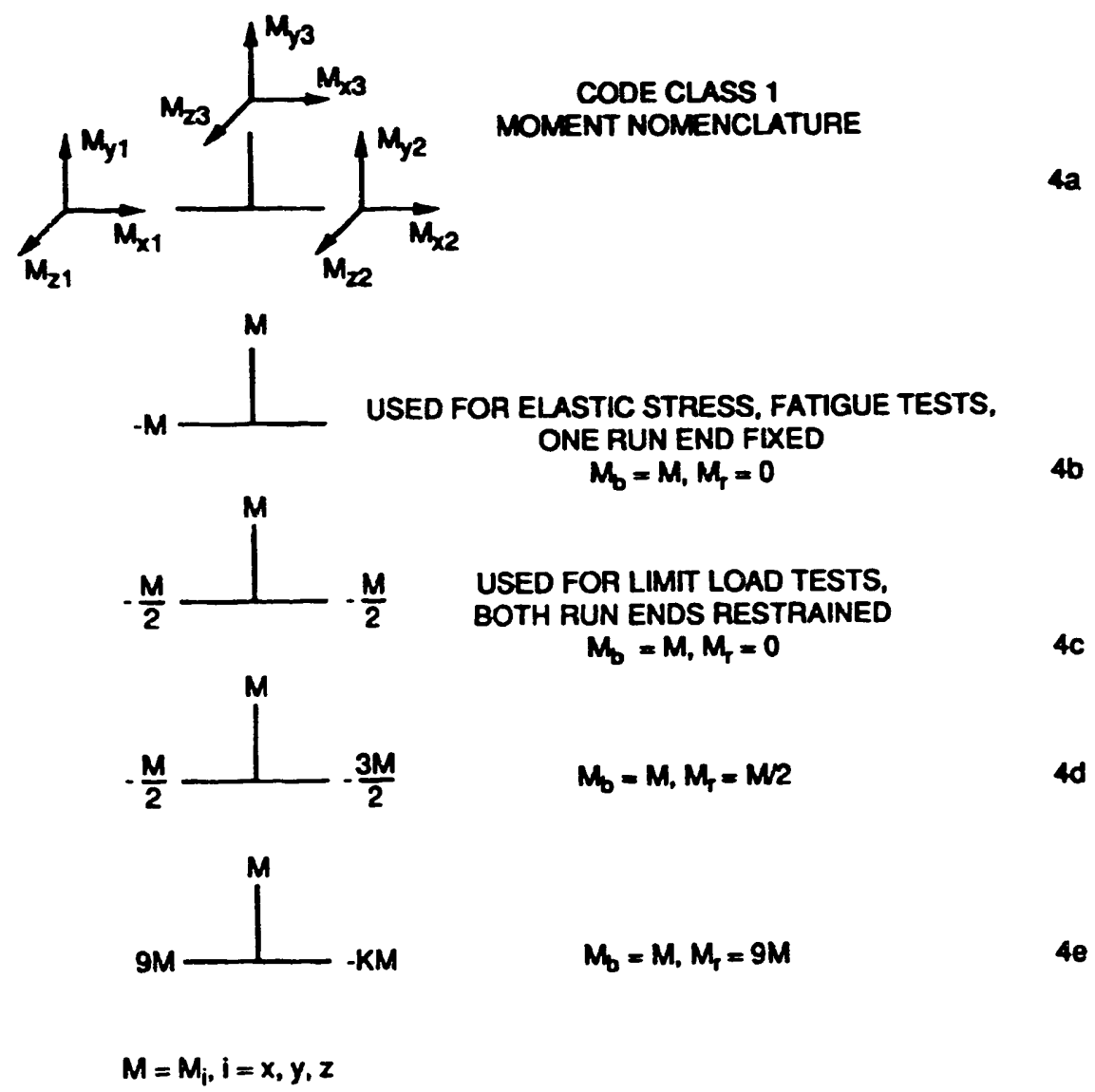

Figure 4. Illustrations of Combined Branch and Run Moments

Dist. Category RM 


\section{INTERNAL DISTRIBUTION}

1. J. M. Corum

2. R. G. Gilliland

3-7. R. C. Gwaltney

8. J. E. Jones Jr.

9-14. S. E. Moore

15. A. B. Poole

16. C. E. Pugh
17. W. F. Swinson

18. G. T. Yahr

19. ORNL Patent Section

20. Central Research Library

21. Document Reference Section

22-23. Laboratory Records Department

24. Laboratory Records (RC)

\section{EXTERNAL DISTRIBUTION}

25. Jffice of Assistant Manager for Energy Research and Development, DOE-OR, Oak Ridge, TN 37831.

26. W. E. Campbell, Jr., U.S. Nuclear Regulatory Commission, Washington, DC 20555.

27. N. C. Chokshi, U.S. Nuclear Regulatory Commission, Washington, DC 20555.

28. W. C. Kroenke, Westinghouse Bettis, 814 Pittsburgh-McKeesport Blvd., P.O. Box 79, West Mifflin, PA 15122.

29-34. E. C. Rodabaugh, 7025 Scribner Way, Dublin, OH 43017.

35. E. A Rodriguez, General Dynamics, Los Alamos Scientific Laboratory, ET-NPR/SPO, P.O. Box 1663, MS-5775, Los Alamos, NM 87545.

36. G. C. Slagis, G. C. Slagis Associates, 3520 Eris Court, Walnut Creek, CA 94598-4669.

37-46. E. O. Woolridge, Division of Engineering, U.S. Nuclear Regulatory Commission, Washington, DC 20555. Distribution as shown in category RM (NTIS-10). 

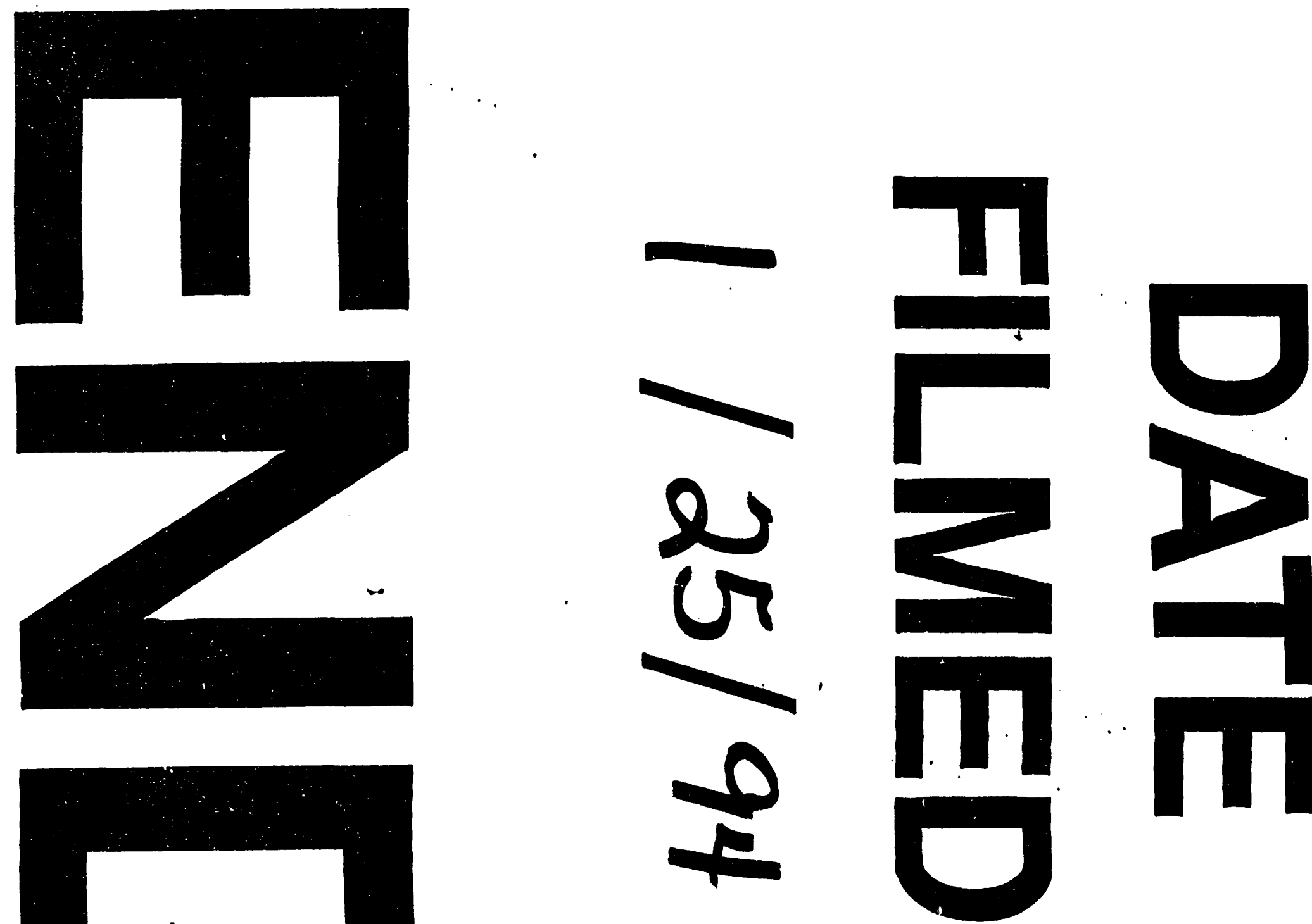

-

\&

v

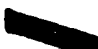


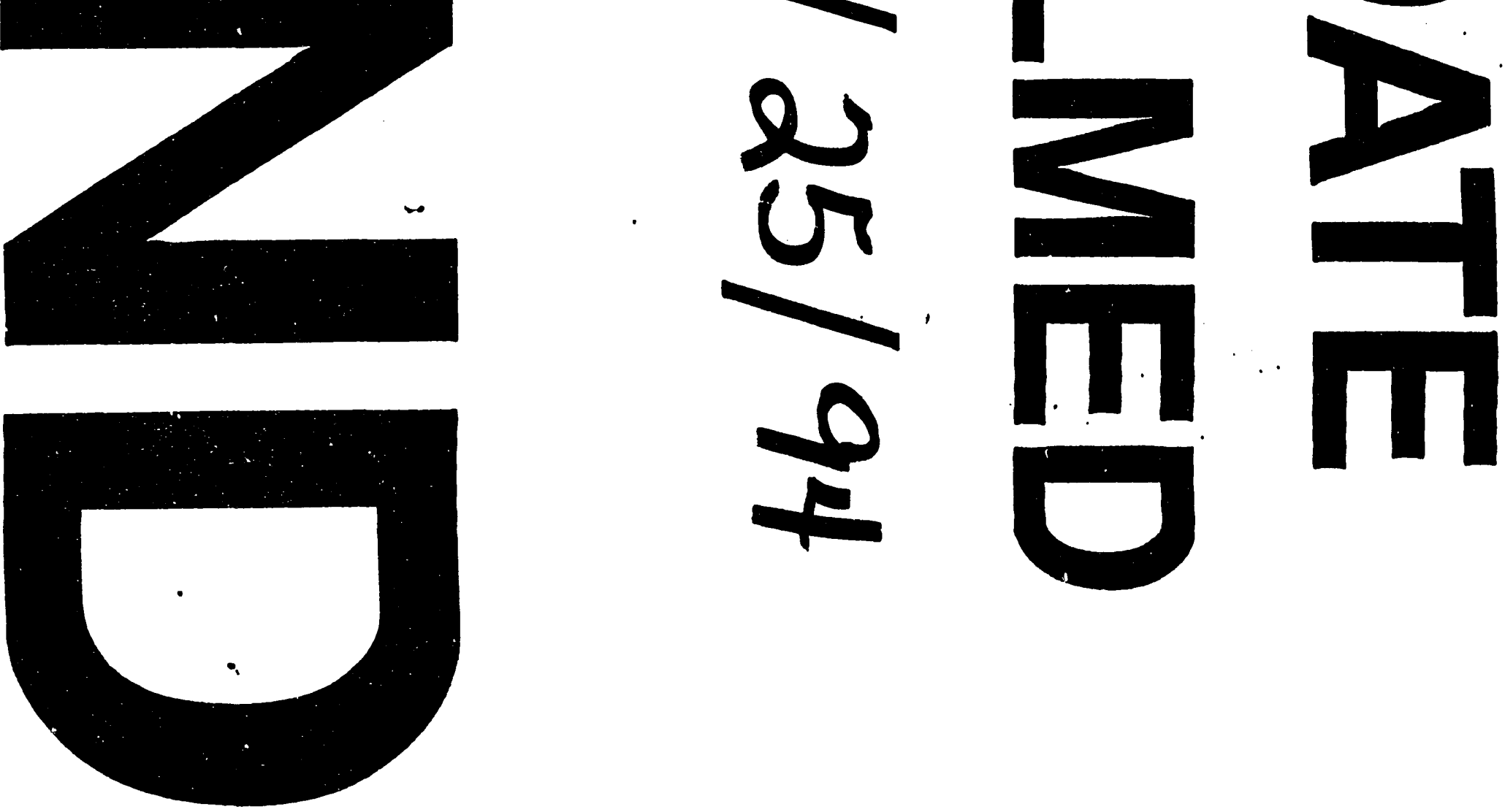